\title{
TOWARDS AN EXPLANATION OF HOUSEHOLD PORTFOLIO CHOICE HETEROGENEITY: NONFINANCIAL INCOME AND PARTICIPATION COST STRUCTURES
}

\author{
Annette Vissing-Jorgensen \\ Working Paper 8884 \\ http://www.nber.org/papers/w8884 \\ NATIONAL BUREAU OF ECONOMIC RESEARCH \\ 1050 Massachusetts Avenue \\ Cambridge, MA 02138 \\ April 2002
}

I thank Ricardo Caballero, Olivier Blanchard, and seminar participants and discussants for many helpful comments. The views expressed herein are those of the authors and not necessarily those of the National Bureau of Economic Research.

(C) 2002 by Annette Vissing-Jorgensen. All rights reserved. Short sections of text, not to exceed two paragraphs, may be quoted without explicit permission provided that full credit, including $\odot$ notice, is given to the source. 
Towards an Explanation of Household Portfolio Choice Heterogeneity:

Nonfinancial Income and Participation Cost Structures

Annette Vissing-Jorgensen

NBER Working Paper No. 8884

April 2002

JEL No. G11, G12

\begin{abstract}
The paper uses micro data on income and asset holdings from the Panel Study of Income Dynamics and other US household level data sets to analyze reasons for nonparticipation in the stock market and for heterogeneity in portfolio choice within the set of stock market participants. I find evidence of a positive effect of mean nonfinancial income on the probability of stock market participation and on the proportion of wealth invested in stocks conditional on being a participant. The volatility of nonfinancial income is found to have a negative impact on these two quantities. However, there is no evidence of an effect of the correlation of nonfinancial income with the stock market return on portfolio choice. Three different costs of stock market participation are considered, a fixed transactions cost, a proportional transactions cost, and a per period participation cost. I find evidence of structural state dependence in the stock market participation decision supporting the importance of fixed transactions costs. This is supported by findings of higher trading frequencies for high wealth households. Based on a simple model of the benefits of stock market participation I estimate that a per period stock market participation cost of just 50 dollars is sufficient to explain the choices of half of stock market nonparticipants.
\end{abstract}

Annette Vissing-Jorgensen

Department of Economics, SS425

University of Chicago

1126 East 59th Street

Chicago, IL 60637

and NBER

vissing@uchicago.edu 


\section{Introduction}

Data on the financial portfolios of US households reveal four facts. First, a large fraction of households do not participate in the stock market at any given point in time. Second, there is substantial turnover in the set of stock market participants. Third, within the set of participants there is substantial heterogeneity in the share of financial wealth invested in stocks. Fourth, for many stock market participants there are large changes in the portfolio shares for equity over time. The first and third facts are well known. I document fact two and four below.

These facts present a challenge to existing portfolio theory. In the standard model of lifetime consumption and portfolio choice of Samuelson (1969) and Merton (1969), (1971), agents live off income generated by their invested wealth. They maximize expected lifetime utility by choosing consumption and a portfolio composed of a conditionally riskless asset and $\mathrm{N}$ risky assets, facing no transactions costs. This model predicts that agents should take positions in all existing assets counter to the frequently observed zero holdings. Thus we should not observe nonparticipation in the stock market or entry or exit over time (facts one and two). The optimal portfolio of risky assets and the split between risky and riskless assets will vary across agents with different preferences, wealth and investment horizon. Conditions on return distributions/utility functions have been derived, under which differences in investment horizon and wealth across agents should not lead to differences in portfolio choice. As shown by Samuelson (1969) investment horizons are irrelevant if agents face a constant investment opportunity set (i.i.d returns). CRRA preferences are sufficient for wealth not to matter. While return predictability, deviations from CRRA utility, and heterogeneity in risk aversion could explain some of the heterogeneity in the share of financial wealth invested in stocks across households (fact three) and time (fact four), it is unlikely that these features can explain all such differences. For example, while return predictability can generate large changes in the optimal share of financial wealth invested in equity over time, such changes would affect all households, counter to the vast amount of idiosyncratic (household specific) movements in equity portfolio shares.

The purpose of this paper is to determine empirically whether accounting for differences in nonfinancial income patterns across households and for stock market participations and transactions costs helps explain the remaining heterogeneity in observed portfolio choices. I concentrate on the decision to hold stocks and the proportion of financial wealth held in stocks.

I consider three types of costs, a per period stock market participation $\operatorname{cost} F^{P}$, a fixed cost of trading stock $F^{T F}$, and a variable cost of trading stock $F^{T V}$. A per period stock market participation cost and a fixed transactions cost both have the potential for explaining 
nonparticipation in the stock market for households with low financial wealth. Combined with fluctuations in financial wealth and/or optimal portfolio shares for stocks, these costs furthermore imply entry and (in the case of the per period cost) exit. Fixed or variable transactions costs have the potential to help explain cross sectional difference in portfolio shares for participants and changes in these portfolio shares over time. If households do not trade stocks, the portfolio share for stocks will fluctuate over time due to stock price changes as well as due to changes in the amount of non-stock wealth.

To determine if any of these costs are important for portfolio choice, I provide several tests. The first set are tests of structural state dependence in the stock market participation decision and are based on panel data on portfolio choice from the Panel Study of Income Dynamics (PSID). ${ }^{1}$ If a fixed transactions cost is present, lagged stock market participation status should be an important predictor of current participation status. The data strongly support this prediction. Households who participated in the stock market in 1984 are 31.8 percentage points more likely to participate in 1989, controlling for age, education, race and income, and accounting for unobserved individual heterogeneity in the propensity to become a stockholder. If furthermore a variable transactions cost is present, households with large amounts invested in stocks in the previous period should be less likely to exit the stock market than stock market participants with smaller investments. This is not supported in the data, suggesting that variable transactions costs are not sufficiently large to affect the decision to exit the stock market. I then turn to additional tests for the presence of a fixed transactions cost using transactions data from the Consumer Expenditure Survey (CEX). I the presence of a fixed transactions cost, households with higher financial wealth should be more likely to trade than others and should keep the share of stocks in their portfolio in a narrower range. These predictions are also supported in the data. I then turn to the per period participation cost. I estimate how large a cost is necessary to explain the choices of the majority of stock market nonparticipants. Thus, while this is not a formal test for the presence of such costs it provides an economic estimate of whether participation costs are a likely explanation of nonparticipation by many households. Using data from the 1989 and 1994 PSID I estimate that a per period cost of around 50 dollars in year 2000 prices, is enough to explain the nonparticipation of half the nonparticipants. This reflects the fact that these households had little or no financial wealth to invest. Interpreting the per period participation cost in terms of hours spent managing investments, a cost of 50 dollars translates into only 5 hours at an hourly wage of 10 dollars per hour. For both 1989 and 1994 a cost of about 260 dollars is enough to explain the choices of 75 percent of nonparticipants. 
Thus while it is not reasonable to claim that participation costs can reconcile the choices of all nonparticipants, modest costs are sufficient to understand the choices of a large part of these households.

Turning to the role for nonfinancial income, this has the potential to help explain the cross sectional differences in equity shares for participants and the changes in these over time. In the presence of participation costs/fixed transactions costs, heterogeneity in optimal portfolio shares conditional on entry can also contribute to explaining which households become stock market participants. The theoretical literature on nonfinancial income and background risk predicts three effects. If nonfinancial income is riskless then the more nonfinancial income a household has relative to its financial wealth, the larger a fraction of financial wealth should be invested in stocks. The intuition is that a riskless nonfinancial income stream is similar to the payoff from a riskless asset. To obtain a desirable overall portfolio mix, a household should therefore adjust its allocation of financial assets towards stocks. But nonfinancial income is typically not riskless. If this 'background risk' is uncorrelated with stocks, then it will (under reasonable conditions on preferences) lead households to behave in a more risk averse way thus implying a lower fraction of financial wealth invested in stocks. Finally, if nonfinancial income is correlated with the stock return this implies a hedging component in the proportion invested in stocks of the opposite sign of the correlation.

To test these predictions I use income data from the PSID, 1983-1992, and three observations of portfolio choice from the 1984, 1989, and 1994 wealth supplements to the PSID. A two step procedure is used, similar to the one followed in previous papers, in which the first step consist of estimating relevant moments of the income processes which are then used as regressors in the second step focusing on portfolio choice. My results are based on sample selection models and document economically important and statistically significant mean and variance effects of nonfinancial income on portfolio choice, both in the equation for stock market participation and in the equation for the proportion of financial wealth invested in stocks conditional on participation. For example, an increase in conditional mean nonfinancial income from the 20th percentile to the 80 th percentile increases the probability of being a stockholder by 12.6 percentage points, when holding the other variables in the regression constant at their means. An increase in the conditional standard deviation mean nonfinancial income from the 20th percentile to the 80th percentile decreases the probability of being a stockholder by 3.8 percentage points. I find no evidence for a correlation effect.

Aside from its importance for understanding portfolio choice and thus the determination 
of prices of financial assets, the question of whether observed heterogeneity is consistent with optimizing behavior has important policy implications. One set of implications concerns household investments for retirement. If the observed heterogeneity in portfolio choice represents a rational response to different economic conditions, this would lead one to be more positive towards private retirement accounts with individual investment choices. Another policy implication concerns the effect of taxation of labor/business income on agents' lifetime utility. A proportional tax will have the effect of decreasing the mean and standard deviation of after-tax labor/business income which will affect agents' consumption and portfolio choice. This effect of taxation has been analyzed by Elmendorf and Kimball (2000). The results documenting strong mean and risk effects of nonfinancial income on portfolio choice, emphasize the importance of this issue.

In terms of related work, the most closely related paper on costs of stock market participation is Mulligan and Sala-i-Martin (2000). They focus on all interest bearing assets and the per period cost of investing in such assets. At an interest rate of 5 percent, they estimate the median cost of holding interest bearing assets to be 111 dollars per year. I focus on stockholdings only and furthermore present a theoretical argument to clarify the assumptions needed for the analysis of per period participation costs. My tests for structural state dependence in the stock market participation decision, allowing for the possibility of unobserved heterogeneity, are to my knowledge new as is the test of whether wealthier stock market participants tend to trade more frequently and have smaller changes in their equity shares. Other related papers on adjustment costs and asset pricing are Luttmer (1999), Marshall and Parekh (1999), and Paiella (1999), who all focus on costs of adjusting consumption. For theoretical simulations on how large entry and/or per period participation cost would make households stay out of the stock market, see Haliassos and Bertaut (1997), Bertaut (1998), and Polkovnichenko (2001). Regarding nonfinancial income, Merton (1971) showed that the existence of riskless nonfinancial income should cause agents with HARA utility to invest a larger fraction of their financial wealth in risky assets (the mean-effect mentioned above). As for the variance-effect Gollier and Pratt (1996) consider the effect of unfair background risks, i.e. risks with nonpositive expected values. In a one period model they show that all familiar DARA utility functions are risk vulnerable, meaning that any unfair background risk makes risk-averse agents behave in a more risk averse way. Viceira (2001) extends this result to a multi-period model in which wealth accumulation is endogenous. Viceira furthermore clearly shows the effect on portfolio choice of the sign of the covariance of labor income innovations with the stock return. Positive covariance of the 
stock return and innovations to permanent or transitory income generates a negative hedging component of asset demand and vice versa. The theory of nonfinancial income can be applied to uninsurable labor income as well as to income from privately held businesses, social security and other sources. Using numerical methods Cocco, Gomes, and Maenhout (2001) show that nonfinancial income has large effects on the optimal equity portfolio share. In their calibration the optimal equity share is 16.2 percent in the absence of nonfinancial income. With nonfinancial income calibrated to match that of a typical high school graduate in the PSID data, the optimal equity share is close to one early in life, declining to around 50 percent at retirement age. The optimal equity share for those in the riskiest occupations considered (agriculture) is substantially lower than for those in less risky occupations (public administration), although the net effect of nonfinancial income is to increase the equity share for all groups shown.

Empirical work testing these predictions is mixed and further evidence thus potentially valuable. Guiso, Jappelli and Terlizzese (1996) find support for the mean and variance effects in Italian data. Gakidis (1998) uses 7 years of income data from the PSID and the 1984 wealth supplement. He estimates labor income processes by education-occupation-age groups and finds support for a positive mean effect of labor income and a significantly negative effect of the probability of zero labor income events on the probability of being a stockholder and on the proportion held in stocks conditional on being a stockholder. Heaton and Lucas (2000) use the 1979-1990 Panel of Individual Tax Return Data and exploit the panel dimension to calculate, by household, the standard deviations of labor income and business income and the covariance of these two income components with the S\&P500 stock return. These are then used as regressors in a regression with the proportion of financial wealth invested in stocks as the dependent variable. Some evidence is found for a variance-effect and a covariance-effect, but the results are inconclusive most likely due to the poor quality of asset data in this data set (asset holdings must be estimated based on information on dividends, interest income and capital gains). Souleles (2001) use data from the Consumer Expenditure Survey to calculate the standard deviation of household consumption growth and the correlation of consumption growth with market returns. He finds that households with more volatile consumption, or a larger consumption-return correlation, hold and buy significantly fewer stocks and other risky securities. ${ }^{2}$

The rest of the paper is organized as follows. Section 2 describes the main data set used, the PSID. Section 3 describes in more detail the four portfolio choice facts motivating the paper. Section 4 turns to the effects of nonfinancial income on portfolio choice. Section 5 concerns the participation/transactions costs and section 6 concludes. 


\section{Data}

The need for a panel of income and portfolio data motivates the use of the Panel Study of Income Dynamics for my analysis. I use the Survey Research Center sample of the PSID which was representative of the civilian noninstitutional population of the US when the study was started in 1968. The PSID tracks all original family units and their adult offspring over time, so with low attrition rates the sample remains representative as long as offsprings are included. To keep the sample representative, I excluded the poverty sample and the Latino sample.

The last year for which final release data are available is 1993. Income data collected in a given year refer to the previous calendar year so the last available income data refer to 1992. From the 1968-93 family files I construct a data set containing information for each of the households ever in the sample during this period. I use the family files rather than the individual files since wealth information is available at the household level. There are 6268 such households (after excluding the poverty and Latino samples) of which around 3500 are in the sample in a given year. For split-offs, information for years prior to the split-off is coded as missing.

Wealth information from the 1984, 1989 and 1994 supplements is used to calculate financial wealth, defined as the sum of cash (checking or savings accounts, money market bonds, or Treasury bills, including such assets held in IRAs), bonds (bond funds, cash value in life insurance policies, valuable collections, rights in trusts or estates), and stocks (shares of stock in publicly held corporations, mutual funds, or investment trusts, including stocks in IRAs). To identify entries for which imputations were used, I use the wealth information as given in the family files instead of the wealth supplement files. Imputed values for cash, bonds or stocks can then be coded as missing. Topcoding of wealth or income variables is very rare in the PSID and topcoded variables were left at their topcodes. Although households in reality can have a portfolio share for a given asset above one, the PSID wealth data does not allow one to observe this due to the way the wealth questions are formulated. For example, the questions asked concerning stockholdings are "Do you (or anyone in your family living there) have any shares of stock in publicly held corporations, mutual funds, or investment trusts, including stocks in IRAs?" and "If you sold all that and paid off anything you owed on it, how much would you have?". Thus, a household who had borrowed to invest more than its total financial wealth in stocks would be recorded as having a portfolio share for stocks of one. Similarly, it is not possible to identify short sales from these questions.

I define nonfinancial income as all taxable income plus transfer income of head and spouse, minus income from dividends, interest, trust funds, and royalties. Income and wealth variables 
are deflated by the consumer price index for all urban consumers, with 1982-84 as basis year (I will refer to this as "1983 prices" below). When estimating conditional moments of nonfinancial income, I use only households with positive financial wealth in 1984 and 1989 for which data were available for all survey years in the period 1984-1993 and who had no change in head or spouse during this period. For the summary statistics given in Table 1 and 2, as well as in Figure 6 and 7 concerning the costs of stock market participation, all households (or all households with positive financial wealth when relevant) are used. Exact sample sizes are given under each table and figure.

The stock return used below for calculating the covariance of stocks and nonfinancial income is the real value weighted NYSE index. To check the robustness of some of my results and to test predictions not testable with the PSID data I will furthermore use data from the Survey of Consumer Finances as well as the Consumer Expenditure Survey. These data sets are described briefly in the relevant sections.

\section{Basic facts about heterogeneity in portfolio choice}

The four portfolio choice facts motivating the paper are as follows. First, a large fraction of US households do not participate in the stock market at a given point in time. Table 1 confirms this fact in the PSID data. In any given year only a fraction of households participates in the stock market. An upward trend in stock market participation is clear in the PSID data. Of households with positive financial wealth 44.1 percent participated in the stock market in 1994, up from 34.0 percent in 1989 and 28.4 percent in 1984 (this includes stockholdings in mutual funds and pension plans). The percent of households with positive financial wealth is 83.4 in $1984,85.5$ in 1989 , and 82.3 in 1994.

A fixed transactions cost and a stock market per period participation cost both have the potential for explaining nonparticipation in the stock market. This explanation is consistent with the fact that the participation rate is strongly increasing in financial wealth (this will be documented in detail below). Furthermore, if nonfinancial income leads to heterogeneity in the

optimal portfolio share across households, this could help explain different participation choices by households with similar wealth.

Second, there is substantial turnover in the set of stock market participants (entry and exit). With three observations of portfolio choice per household in the PSID, it is possible to analyze patterns of participation and portfolio shares over time. Many papers have emphasized 
widespread non-participation in the stock and/or bond market based on a cross-section of households. By following households over time it is possible to determine whether households either tend to stay in/stay out of a given market or whether there is widespread movements in and out of markets. The results are shown in Figures 1 to 3 and Table 2, all based on PSID households with positive financial wealth. Figure 1a focuses on the set of households for which portfolio information is available for both 1989 and 1994. The figure plots the 1994 share of financial wealth held in stocks against the 1989 share. Somewhat surprisingly, many households participate in the stock market in one year but not the other. These are the points along the axes forming an angle in the graph. 27.6 percent of households are on this 'angle', not including the origin. Points on the horizontal axis correspond to exits, whereas points on the vertical line correspond to entry. An additional 43.1 percent are at the origin. Figure 1b shows similar results based on the 1984-89 panel. Notice that many of the points on the angles are far from zero. This reflects households who move from a zero to a substantially positive fraction of wealth in stocks or the other way around and for which the entry/exit thus does not correspond to 'marginal' changes in stockholdings as a percentage of financial wealth. These patterns remain if households with low financial wealth are dropped. Figure 1c focuses on households with positive financial wealth for which three observations of portfolio choice are available. The change in the share of financial wealth held in stocks between 1989 and 1994 is plotted against the 1984-89 change. A 'triplet' of lines is apparent. The vertical line corresponds to households who did not participate in the stock market in 1984 or 1989 but did participate in 1994 (points showing zero change between 1984 and 1989 are all for non-participant who had a zero share in both years). The horizontal line corresponds to households who participated in 1984 but not in 1989 or 1994 . The last interesting line is the downward sloping one, which shows that many households entered the stock market some time between 1984 and 1989, but left the market again some time between 1989 and 1994. It is tempting to interpret this as households who entered but were scared by the market crash in October 1987. However, Figure 2c shows a similar pattern for bond holdings. A more plausible explanation for this pattern is large changes in financial wealth and/or optimal portfolio shares combined with a fixed per period cost of participating in the market (some amount of measurement error is also likely). The graphs for the remaining component of financial wealth, cash, are shown in Figure 3. The lines are the 'reverse' of those shown in Figures 1 and 2 as would be expected. See also Hurst, Luoh and Stafford (1998) for a discussion of the entry and exit probabilities for stockownership in the PSID.

A per period participation cost can explain why households do not participate when they 
have low financial wealth. This will imply entry and exit if wealth fluctuates over time. This is consistent with the fact that wealth change is a very strong predictor of stock market entry and exit. For example, of those who entered the stock market between 1989 and 1994, 88 percent had an increase in financial wealth over the period, compared to 40 percent for those who stayed out of the stock market. Of those who exited the stock market between 1989 and 1994, only 27 percent had an increase in financial wealth over the period, compared to 78 percent for those who stayed in the stock market. Thus while financial wealth changes alone do not explain all entry/exit decisions it is likely to be an important factor.

The third portfolio fact it is that within the set of participants there is substantial heterogeneity in the share of financial wealth invested in stocks. This is clear from the dispersion of portfolio shares for stocks in Figure 1. The proportion of financial wealth invested in stocks for stock market participants has a cross-sectional standard deviation around 30 percentage points in each of the years 1984, 1989, and 1994.

Finally, the fourth fact is that even for continuing stock market participants there are large changes in the portfolio shares for equity over time. This is again clear from Figure 1. For continuing stock market participants, the change in the proportion of financial wealth invested in stocks has a cross-sectional standard deviation of 34.3 for the 1984-1989 panel and 37.0 for the 1989-94 panel.

Fixed or variable transactions costs have the potential to help explaining fact three and four. If households do not trade stocks, the portfolio share for stocks will fluctuate over time due to stock price changes as well as due to changes in the amount of non-stock wealth. The most comprehensive data on equity trading by households is the study "Equity Ownership in America" by the Investment Company Institute (1999). The study documents that many households trade only very infrequently. The study was performed in early 1999 and is representative of US households. Of the 4842 respondents 48.2 percent held equities. Of stockholders, 38 percent held both individual stocks and stock mutual funds, 15 percent held only individual stocks, while 47 percent only held stock mutual funds. Consistent with the presence of (fixed or variable) transactions costs 55 percent of stockholders did not conduct any equity transactions in 1998. The 45 percent of stockholders who did conduct one or more equity transactions in 1998 were composed of 15 percentage point who conducted one or two transactions, 19 percentage points who conducted between 3 and 12 transactions, and 11 percentage points who conducted more than 12 transactions. Consistent with the findings of Ameriks and Zeldes (2000) for TIAA-CREF participants, trading activity was especially rare for stocks held inside employer 
sponsored retirement plans. Of equity owners with equities held through a such plan only 22 percent changed the allocation of their plan holdings, and only 24 percent made a change in how their contributions were to be invested. Therefore, despite the impression one may get from the increase in online trading during the 1990s, trading is still infrequent for most households with more than half of stockholders conducting no stock transactions in 1998.

\section{Effects of nonfinancial income on portfolio choice}

\subsection{Framework for estimating the conditional moments of nonfinancial in- come}

Let $\mu_{i t}=E\left(Y_{i t} \mid Y_{i, t-1}, X_{i, t-1}\right)$ and $\sigma_{i t}=\sqrt{V\left(Y_{i, t} \mid Y_{i, t-1}, X_{i, t-1}\right)}$ where $Y_{i t}$ is the nonfinancial income of household $i$ in period $t$ and $X_{i, t-1}$ is a vector of variables useful for predicting next period income for household $i$. Furthermore, denote by $\rho_{i t}$ the conditional correlation between shocks to log nonfinancial income and the log stock return, and let $W_{i t}$ be the financial wealth of household $i$ at date $t$.

For the proportion of financial wealth invested in stocks, theory predicts that the relevant moments to include as regressors are scaled by financial wealth $W_{i t}: \frac{\mu_{i t}}{W_{i, t}}, \frac{\sigma_{i t}}{W_{i t}}$, and $\frac{\mu_{i t}}{W_{i t}} \rho_{i t}$. I interact the correlation measure $\rho_{i t}$ with $\frac{\mu_{i t}}{W_{i t}}$ since the correlation is more relevant the more nonfinancial income a household has on average. With fixed transactions and/or participation costs, the decision of whether to hold stocks or not depends on the optimal dollar amount to be invested conditional on entry. Thus the relevant moments are the above, without scaling by financial wealth: $\mu_{i t}, \sigma_{i t}$ and $\mu_{i t} \rho_{i t}$.

I follow a framework for estimating the conditional moments of nonfinancial income similar to that of Carroll and Samwick (1997). Log nonfinancial income of household $i$ at date $t, \ln Y_{i t}$, is assumed to consist of two components, $p_{i t}$ and $\varepsilon_{i t}$. The first component, denoted 'permanent income', is a random walk with a drift term $g_{i t}$. The drift term is perfectly predictable based on the household's information at $t-1, I_{i, t-1}=\left(Y_{i, t-1}, X_{i, t-1}\right)$. The second component, denoted 'transitory income' is an i.i.d. shock. I assume that all shocks are normally distributed and 
uncorrelated. Thus the income process is as follows:

$$
\begin{aligned}
\ln Y_{i t} & =p_{i t}+\varepsilon_{i t}, p_{i t}=g_{i t}+p_{i, t-1}+\eta_{i t} \\
\varepsilon_{i t} & \sim N\left(0, \sigma_{\varepsilon i}^{2}\right), \eta_{i t} \sim N\left(0, \sigma_{\eta i}^{2}\right), \\
\operatorname{cov}\left(\varepsilon_{i t}, \varepsilon_{i s}\right)= & 0, \forall t \neq s, \operatorname{cov}\left(\eta_{i t}, \eta_{i s}\right)=0, \forall t \neq s, \operatorname{cov}\left(\varepsilon_{i t}, \eta_{i s}\right)=0, \forall t, s \\
& g_{i t} \text { known based on } I_{i, t-1} \\
\Downarrow & \\
\ln Y_{i t}-\ln Y_{i t-1} & =p_{i t}-p_{i, t-1}+\varepsilon_{i t}-\varepsilon_{i, t-1}=g_{i t}+\eta_{i t}+\varepsilon_{i t}-\varepsilon_{i, t-1} \Longleftrightarrow \\
\ln Y_{i t} & =\ln Y_{i, t-1}+g_{i t}+\eta_{i t}+\varepsilon_{i t}-\varepsilon_{i, t-1} .
\end{aligned}
$$

This implies that

$$
\begin{aligned}
E\left(\ln Y_{i t} \mid \ln Y_{i, t-1}, X_{i, t-1}\right) & =\ln Y_{i, t-1}+g_{i t} \\
V\left(\ln Y_{i t} \mid \ln Y_{i, t-1}, X_{i, t-1}\right) & =\sigma_{\eta i}^{2}+2 \sigma_{\varepsilon i}^{2} \\
\mu_{i t} & =E\left(Y_{i t} \mid Y_{i, t-1}, X_{i, t-1}\right)=e^{\left(\ln Y_{i, t-1}+g_{i t}\right)+\frac{1}{2}\left(\sigma_{\eta i}^{2}+2 \sigma_{\varepsilon i}^{2}\right)} \\
& =Y_{i, t-1} G_{i t} e^{\frac{1}{2}\left(\sigma_{\eta i}^{2}+2 \sigma_{\varepsilon i}^{2}\right)} \\
\sigma_{i t}^{2} & =V\left(Y_{i t} \mid Y_{i, t-1}, X_{i, t-1}\right) \\
& =e^{2\left(\ln Y_{i, t-1}+g_{i t}\right)+\left(\sigma_{\eta i}^{2}+2 \sigma_{\varepsilon i}^{2}\right)}\left(e^{\left(\sigma_{\eta i}^{2}+2 \sigma_{\varepsilon i}^{2}\right)}-1\right) \\
& =\left(Y_{i, t-1} G_{i t}\right)^{2} e^{\left(\sigma_{\eta i}^{2}+2 \sigma_{\varepsilon i}^{2}\right)}\left(e^{\left(\sigma_{\eta i}^{2}+2 \sigma_{\varepsilon i}^{2}\right)}-1\right)
\end{aligned}
$$

where $X_{i, t-1}$ are the variables in $I_{i, t-1}$ relevant for predicting $g_{i t}$ and $G_{i t}=e^{g_{i t}}$.

The issue arises which data should be used for estimating $\sigma_{\eta i}^{2}+2 \sigma_{\varepsilon i}^{2}$ in order to construct estimates of $\mu_{i t}$ and $\sigma_{i t}$ for each household at each date $t$ at which portfolio data are available. It is unlikely that $\sigma_{\eta i}^{2}+2 \sigma_{\varepsilon i}^{2}$ is constant over time, since e.g. a change from employed to retired would imply a switch to a nonfinancial income process with different parameters. Therefore, it would not be appropriate to use all available income data for each household to estimate $\sigma_{\eta i}^{2}+2 \sigma_{\varepsilon i}^{2}$. Instead, I use income data and data for $X$ for a window of years after a given portfolio observation to obtain (for each household) an estimate $\sigma_{\eta i}^{2}+2 \sigma_{\varepsilon i}^{2}$ valid for that year. In the PSID, portfolio data are available for 1984, 1989, and 1994, whereas income data are available annually. Since income data are available up to 1992 only, the 1994 portfolio data cannot be used for the analysis of the effect of nonfinancial income, since income moments cannot be constructed. The relevant portfolio observations for this part are thus from 1984 and 
1989. For 1984 I use the consumption growth observations for the years 1984-1988 (i.e. five consumption growth observations based on data for 1983-88) for estimating $\sigma_{\eta}^{2}+2 \sigma_{\varepsilon}^{2}$. For $1989 \mathrm{I}$ use the years 1989-1992 (i.e. four consumption growth observations based on data for 1988-92).

For each of the two windows of years, $\ln Y_{i t}-\ln Y_{i, t-1}$ is regressed on the vector of variables $X_{i, t-1}$. The predicted values are used as an estimate of $g_{i t}$ and the residuals as an estimate of $\eta_{i t}+\varepsilon_{i t}-\varepsilon_{i, t-1}$. This is done separately for the window after 1984 and for the window after 1989 . For $X_{i, t-1}$ I use age of household head, age of household head squared, one digit occupation and industry dummies, number of children under 18, a dummy for being married, a dummy for being white, and three education dummies (16+ years, 13-15 years and 9-12 years of education, respectively). ${ }^{3}$ The $R^{2 \prime}$ s from these two regressions are tiny (around 0.01) although many of the regressors are significant. Results are similar if $g_{i t}$ is simply assumed constant implying that income growth is unpredictable. The sample variance of the residuals for each household are then used to estimate $\sigma_{\eta i}^{2}+2 \sigma_{\varepsilon i}^{2}$. Since this involves estimating $\sigma_{\eta i}^{2}+2 \sigma_{\varepsilon i}^{2}$ with only 5 observations (4 observations for the window after 1989), I do not attempt to estimate $\sigma_{\eta i}^{2}$ and $\sigma_{\varepsilon i}^{2}$ separately. Given estimates of $\sigma_{\eta i}^{2}+2 \sigma_{\varepsilon i}^{2}$ for each household, the moments $\mu_{i t}$ and $\sigma_{i t}$ can then be calculated at the household level. Due to the estimation error in $\sigma_{\eta i}^{2}+2 \sigma_{\varepsilon i}^{2}$ and potential measurement error in $Y_{i, t-1}$, the estimates of $\mu_{i t}$ and $\sigma_{i t}$ are likely to be noisy estimates of households' expectations about these variables. I therefore estimate the portfolio model first using the estimates of $\mu_{i t}$ and $\sigma_{i t}$ and then (for comparison) using instrumental variables techniques.

Estimating the conditional correlation $\rho_{i t}$ between $\eta_{i t}+\varepsilon_{i t}-\varepsilon_{i t-1}$ and the log gross stock return $\ln \left(1+r_{s, t}\right)$ with only 5 observations is likely to give very imprecise estimates (estimates for the two windows showed very little correlation which most likely reflects large estimation errors). I therefore use the combined window from 1983-1992.

\subsection{Findings}

I estimate a sample selection model, since I am interested in both the discrete decision to participate in the stock market as well as the proportion of financial wealth invested in stocks conditional on participation. Let $S_{i t}$ be an indicator for whether household $i$ participates in the stock market at date $t$, and denote by $\alpha_{i t}$ the fraction of financial wealth invested in stocks. Also, let $D_{i t}=\alpha_{i t} W_{i t}$ denote the dollar amount invested in stocks. The sample selection model 
is then

Participation equation : $S_{i t}^{*}=x_{i t}^{\prime} \beta+\delta_{1} S_{i, t-1}+\delta_{2} D_{i, t-1}+\delta_{3} D_{i, t-1}^{2}+\nu_{i t}, S_{i t}=\left\{\begin{array}{l}1 \text { if } S_{i t}^{*} \geq 0 \\ 0 \text { otherwise }\end{array}\right.$

Equity share equation : $\alpha_{i t}=w_{i t}^{\prime} \gamma+u_{i t}$, observed if $S_{i t}=1$.

The model is estimated using maximum-likelihood estimation. The regressors $x_{i t}$ and $w_{i t}$ include the moments of nonfinancial income as well as controls discussed below. The participation equation furthermore includes lags of the participation indicator, the lagged dollar amount invested in stocks, and the lagged dollar amount squared. The inclusion of these lags are motivated by the transactions costs $F^{T F}$ and $F^{T V}$ and is discussed in detail in the section on structural state dependence below.

Estimating a separate probit model for the participation decision would provide consistent estimates of the parameters in the participation equation. However, a linear regression for the proportion of financial wealth invested in stocks conditional on participation with no correction for selection of households into the group of stock market participants would not provide consistent estimates of the effects of the conditional moments of nonfinancial income or other regressors if $\nu_{i t}$ and $u_{i t}$ are correlated. This is the case since $E\left(u_{i t} \mid w_{i t}, S_{i t}=1\right) \neq 0$ when $\operatorname{cov}\left(\varepsilon_{i t}, \nu_{i t}\right) \neq 0$ even if $E\left(u_{i t} \mid w_{i t}\right)=0$. By accounting for the correlation of the error terms the joint estimation of the two decisions leads to consistent estimates of the parameters in both equations.

In addition to the conditional moments of nonfinancial income, I include the following controls in both the participation and the equity share equations.

$W_{i t}, W_{i t}^{2}$ : Financial wealth of household $i$ at the beginning of period $t$, and the square of this variable. In the participation equation, financial wealth will have a positive effect on the probability of being a stock market participant if any of the fixed costs, $F^{T F}$ and $F^{P}$, are important and the optimal dollar amount invested is increasing in wealth (as would be the case for utility functions of the DARA type). If risk aversion declines faster/slower in financial wealth than it does in the CRRA utility case, financial wealth will also have an effect in the equity share equation.

Age $_{i t}$, Age $_{i t}^{2}$ (of the head of household): Age and age squared of the head of household (the male in couples). With finite lifetimes the investment horizon depends on age. If investment opportunities are time varying, optimal portfolio choice depends on the investment horizon and thus on age. Age could also matter for other reasons, for example because of age dependent health risks. 
Education $_{i t}$, Race $_{i t}$ (of the head of household): Education and/or race could be significant in the participation equation if any of the fixed costs differ across education or racial groups. Furthermore, education or race could be significant in both the participation and the equity share equation if risk aversion differ across education or racial groups.

Table 3 shows the results for the sample selection model estimated on the baseline sample of 1081 households using portfolio data from 1989 as well as 1984 for the lags. The sample is smaller than in Tables 1 and 2 since I now focus on households with positive financial wealth in 1984 and 1989 for which data were available for all survey years in the period 1984-1993 and who had no change in head or spouse during this period. Furthermore, I drop households for which any of the variables $\mu_{i t}, \sigma_{i t}, \frac{\mu_{i t}}{W_{i t}}, \frac{\sigma_{i t}}{W_{i t}}$, or the lags of these used as instruments below, are in the top or bottom one percent of observations for that variable. This is done to diminish the effect of outliers.

There is clear evidence of a positive mean-effect and a negative risk-effect of nonfinancial income in both equations. The effects are economically important as well as statistically significant. An increase in conditional mean nonfinancial income from the 20th percentile $(\$ 18,742$ in 1983 prices) to the 80 th percentile $(\$ 56,428)$ increases the probability of being a stockholder by 12.6 percentage points, when holding the other variables in the regression constant at their means. An increase in the (annual) conditional standard deviation mean nonfinancial income from the 20th percentile $(\$ 2569)$ to the 80 th percentile $(\$ 13075)$ decreases the probability of being a stockholder by 3.8 percentage points, again holding the other variables in the regression constant at their means. In the baseline regression, the effects in the equity share equation are fairly small. However, they will be much bigger when instrumenting below. For the sample of stockholders the 20th and 80th percentiles of $\frac{\mu_{i t}}{W_{i t}}$ are 0.45 and 4.55 , respectively. A such move increases the proportion invested in stocks by 3.1 percentage points. The 20 th and 80 th percentiles of $\frac{\sigma_{i t}}{W_{i t}}$ for stockholders are 0.08 and 0.92 , with an implied effect on the proportion invested in stocks of -1.9 percentage points.

Education enters the regressions with the same signs as has been found in other studies. Households the head of which is more educated are more likely to hold stocks and to hold a larger proportion of their wealth in stocks. Only the effect of education in the participation equation is statistically significant. I will return to the interpretation of this below in the context of the lags included in that equation. Of the other controls, financial wealth is found to be a very strong determinant of the decision to participate in the stock market, consistent with a fixed cost of participation or a fixed transactions cost. I will elaborate on this in the section on 
costs of stock market participation below.

The results of estimating the model using instrumental variables are shown in Table 4. Estimation error in $\sigma_{\eta i}^{2}+2 \sigma_{\varepsilon i}^{2}$ and potential measurement error in $Y_{i, t-1}$, cause the estimates of $\mu_{i t}$ and $\sigma_{i t}$ to be noisy estimates of households' expectations about these variables. This will lead to inconsistent estimates unless instrumental variables estimation is used. The 1984 estimates of $\mu_{i t}, \sigma_{i t}$ for the participation equation and of $\frac{\mu_{i t}}{W_{i t}}, \frac{\sigma_{i t}}{W_{i t}}$ for the equity share equation are used as instruments for the 1989 values. Regressions of each of $\mu_{i t}, \sigma_{i t}, \frac{\mu_{i t}}{W_{i t}}$, and $\frac{\sigma_{i t}}{W_{i t}}$ on the lags used as instruments produce $R^{2}$ values of $0.51,0.06,0.09$, and 0.07 . The instruments are in all cases significant at the 1 percent level. This suggests that the instruments are reasonably strong predictors of the variables they are instrumenting for. ${ }^{4}$ The IV estimation is done separately for the participation equation and the equity share equation. For the participation equation, I use the IV estimator for probit models described in Amemiya (1978) (any of the IV estimators described by Amemiya are equivalent here, since the present model is just identified). For the equity share equation I use the IV estimator from Lee (1981) which accounts for selection.

In the participation equation, the effects of the conditional moments are similar to the baseline case without instrumenting, although $\sigma_{i t}$ is no longer significant. In the equity share equation, the effects of the conditional moments are dramatically larger when instrumenting. Moving a household from the 20th to the 80th percentile of $\frac{\mu_{i t}}{W_{i, t}}$ now leads to an increase in $\alpha$ by as much as 20.0 percentage points. A similar move in $\frac{\sigma_{i t}}{W_{i t}}$ now implies a decrease in $\alpha$ of 8.2 percentage points. Overall, the IV results show the importance of instrumenting for the conditional moments given the likely estimation error in these.

Turning to the correlation effect, Table 5 repeats the estimation from Table 3 but including the correlation variables. There is no evidence of a correlation effect in either equation. This may be due to the difficulty of estimating the correlations with a relatively short time series dimension.

In sum, the results support the theoretical prediction of a positive effect of mean nonfinancial income on the probability of stockholding and the optimal share of financial wealth invested in stocks, and of a negative effect of the volatility of nonfinancial income. I find no evidence of a correlation effect.

Further evidence of the mean and risk effects of nonfinancial income can be obtained from the Survey of Consumer Finances (SCF) which for 1995 and 1998 contains self-reported measures of expected income and income risk. The SCF consist of repeated cross sections of about 4000 US households and is thus not a panel like the PSID. Table 6 shows the results of probit models of 
stock market participation based on the SCF data. I focus on probit models of the participation decision only since the SCF only has categorial information about the proportions allocated to equity for indirect stockholdings (pension plans, mutual funds, trusts etc.). The regressor labelled 'normal income' is the response to the question "About what would your income have been if it had been a normal year?". The dummy for next year's income being uncertain is based on the question "At this time, do you have a good idea of what your income for next year will be?". For comparison with the PSID, households included in the two samples are those who had positive financial wealth and who did not have normal income in the highest or lowest percentile. The estimations are done using all SCF imputations for missing values (t-statistics are correspondingly divided by $\sqrt{5}$ ). For comparison with the PSID, the estimations use SCF weights and I exclude the households with normal income in the bottom one percent or top one percent (accounting for the households weights). The number of observations used is 3379 for the 1995 SCF and 3444 for the 1998 SCF. The effect of normal income on the probability of being a stock market participant is again statistically significant and of a similar order of magnitude as the effect found in the PSID. Moving a household from the 20th to the 80th percentile of normal income, holding the other regressors fixed at their means, increases the probability of being a stockholder by 11.4 percentage points in the 1995 data and 13.6 percentage points in the 1998 data. As for the risk measure, households who do not have a good idea of next year's income are 5.4 percentage points less likely to be stockholders in 1995 and 9.8 percentage points less likely in 1998.

If nonfinancial income risk matters because households cannot insure against it (as is the maintained hypothesis in the literature), then we should see that households who report being borrowing constrained are less likely to hold stocks. The next two regressors in Table 6 are indicator variables of being borrowing constrained. The strongest measure of being borrowing constained, $\mathrm{D}$ (deterred from applying for credit), is one if during the past five year's the household thought of applying for credit but changed its mind thinking it may be turned down. Households who were deterred from applying for credit were about 10.8 percentage points less likely to hold stocks in the 1995 data and about 5.6 percentage points less likely in the 1998 data. A second measure of borrowing constaints is the dummy variable $\mathrm{D}$ (turned down for credit) which is one if the household has been turned down for credit during the last five years (and been unable to borrow the requested amount from another lender). Having been turned down for credit has a negative effect on the probability of being a stockholder only in the 1995 data. 
Overall the SCF data support the findings based on the PSID of a positive mean effect and a negative risk effect on the probability of stock market participation and provide suggestive evidence that the effect of nonfinancial income risk may be due to borrowing constraints as suggested by theory.

An issue which I have not addressed so far is the possible effect of preference heterogeneity across households. Suppose that households are heterogeneous in terms of their coefficient of relative risk aversion but that we do not include household level risk aversion measures. Less risk averse households are more likely to be stockholders and hold more stocks conditional on participation. However, they are also more likely to self-select into riskier jobs and will therefore tend to have higher standard deviation of labor/business income, and also higher mean labor/business income to the extent the risk is compensated by a higher mean. Thus the regressors will be correlated with the error term. The effect of mean income will be exaggerated and we may get an unexpected positive or insignificant coefficient for labor (business) income risk on stockholdings (similar problems arise for the covariance effect as for the risk effect). The SCF contains a self-reported measure of risk aversion which several papers have found significant in regressions involving stockholdings, see e.g. Haliassos and Bertaut (1995). This is also the case in my results in Table 6 where this measure is included. The effects of 'normal income' and of the uncertainty dummy are a bit larger in absolute value when leaving out the risk aversion measure (not shown). As for the PSID, the 1996 questionnaire for the first time includes a series of questions designed to provide an estimate of relative risk aversion (or equivalently the inverse of relative risk aversion called risk tolerance). The methodology used is the same as the one described in Barsky et al. (1997). The PSID risk aversion questions are only asked of employed respondents. By using the household identification numbers in the 1994-96 early release files the estimates of risk tolerance can be merged back into the sample. The risk tolerance estimate can then be included in an estimation for the 1989 cross-section. I reestimated the model from Table 3 on the subsample for which the risk aversion measure is available. Results were similar to those in Table 3, and were similar whether including the risk aversion measure or not. While these risk aversion measures are not fully satisfactory as controls for individual specific effects, risk aversions heterogeneity is likely to one of the main components of such effects. 


\section{Costs of stock market participation}

Consider the optimization problem of a household that maximizes expected lifetime utility given an exogenous stream of nonfinancial income and faced with the opportunity to invest in two assets, a risky asset and a conditionally riskless asset. The risky asset represents the stock market. The riskless asset is a catchall for less risky financial assets such as bonds, T-bills, bank accounts etc. I assume it is costless to invest in the riskless asset whereas investing in stocks may involve the following three types of costs.

$F^{T F}$ : Fixed cost of trading stock. For first time buyers, this cost represents the time/money spent understanding basic investment principles as well as acquiring enough information about risks and returns to determine the household's optimal mix between stocks and T-bills. Add to that the cost of time spent setting up accounts. For first time buyers as well as others, $F^{T F}$ furthermore includes the fixed part of brokerage commissions, as well as the value of time spend implementing the trade. ${ }^{5}$

$F^{T V}$ : Variable (proportional) cost of trading stock. For directly held stocks, this cost represents the bid-ask spread and the variable part of brokerage commissions. Jones (2001) document a quite strong decline in NYSE average one-way transactions costs (commissions plus half of the bid-ask spread) since the mid 1970s, from around 1.10 percentage point in 1970 to around 0.20 percentage in the late 1990s. Consistent with the importance of trading costs turnover has increased dramatically over the same period (of course, reverse causality cannot be ruled out based on these aggregate data). Indirect holding of stocks also involve transactions costs. For load mutual funds the front load paid upon entry into the fund would also enter $F^{T V}$. Rea and Reid (1998) estimate the average front-end sales load for a sample of load funds, with maximum allowed front-end sales loads (according to their prospectuses) of at least 3 percent, to be 2.3 percent in 1997 down from 4.9 percent in 1982. In addition to this, or as an alternative, some funds have contingent deferred sales loads requiring investors to pay a certain percentage of their initial investment if they sell their mutual fund shares before a given number of years. These again work as a variable transactions cost. For the majority of individual households, the price impact of trades are unlikely to be substantial and thus unlikely to be a main component of $F^{T V}$.

$F^{P}$ : Per period stock market participation cost. This cost represents time spent throughout the year determining if trading is optimal. With time varying conditional asset return distributions, the theory of dynamic hedging suggests that households should actively follow the stock market in order to form more precise expectations of future returns and change their portfolios 
accordingly. Furthermore, for households who attempt to gather information to benefit from buying individual stocks or subcomponents of the stock market index, the cost of this would be included in $F^{P}$. As an example, the increased number of TV programs about the stock market during recent years - a time with large increases in stock market participation - suggests that households do indeed spend time following the market (although part of this may be considered entertainment and thus not be costly). A more subtle part of $F^{P}$ is that it complicates tax returns. According to IRS numbers for 1999, households who have to fill out schedule D and D1 (the schedules for capital gains and losses) on average spend 6 hours and 43 minutes on this.

The above emphasizes costs of acquiring information as an important element of $F^{T F}$ and $F^{P}$. Several recent papers find evidence that households who report to be better informed about financial issues make portfolio decisions more in line with theoretical predictions by having a higher probability of owning risky financial assets and holding a larger number of financial asset classes. See Guiso and Jappelli (2002) for evidence based on Italian data, Alessie, Hochguertel and van Soest (2002) for results based on Dutch data, and Borsch-Supan and Eymann (2002) for findings from German data. While these relations may not be causal, other papers suggest a causal effect of information on savings and portfolio choice. Chiteji and Stafford (2000) find that parental stockholding has a strong effect on the probability that children become stockholders, controlling for economic and demographic characteristic of the children as well as for bequests. This suggest the importance of education about financial matters for stock market participation. Duflo and Saez (2000) study retirement plan choices among the employees in various departments of a particular university. They find that the decision to enroll in a tax deferred account (and the choice of mutual fund vendor for people who enroll) are affected by the decisions of other employees in the same department. Information flow from collegues is a plausible explanation for such effects. Hong, Kubik, and Stein (2001) provide related evidence of peer effects. Bernheim, Garrett and Maki (2001) find that the savings rate of households in the relevant age groups who grew up in a state with a high school financial curriculum mandate was about 1.5 pct points higher than for others in the same age group. Bernheim and Garrett(2001) find similar effects of employer-based retirement education plans.

\subsection{Transactions costs}

\subsubsection{Structural state dependence in stock market participation}

Testable implications Solving a household's optimization problem in the presence of several types of stock market participation costs as well as stochastic nonfinancial income is very difficult 
and to my knowledge has not been done. ${ }^{6}$ Rather than providing simulation evidence, I derive basic testable implications of $F^{T F}$ and $F^{T V}$ concerning structural state dependence in the portfolio decision based on comparison of budget sets. These predictions are valid whether $F^{P}$ is zero or not. I return to $F^{P}$ in the following sections.

Consider a household that lives for several periods. In each period it decides how much to consume and how much to invest in stocks and in the riskless asset. I use the following notation. Households $i$ 's consumption in period $t$ is denoted by $C_{i t}$. Its financial wealth at date $t$ is denoted by $W_{i t}$ and its nonfinancial income in period $t$ by $Y_{i t}$, as above. In terms of asset holdings, let $N_{i t}$ denote the number of stocks the household owns at date $t$ after potential trades, and let $\alpha_{i t}$ refer to the proportion of financial wealth which the household holds in stocks, again after potential trades. $I($.$) is an indicator function equal to one if the argument is true and zero otherwise.$ $S_{i t}$ is the indicator variable for being a stockholder at date $t$. As for the asset returns, let $r_{f, t+1}$ denote the net return on T-bills held from date $t$ to $t+1$ (period $t$ ), and $r_{s, t+1}$ the net return on stocks before paying transactions and/or participation costs.

At date $t$ the household decides on consumption $C_{i t}$ as well as on its stock holdings $N_{i t}$ (and implied bond holdings). If the household decides to not participate in the stock market in period $t$, thus choosing $N_{i t}=0$, its current period budget constraint is

$$
W_{i, t+1}=\left(W_{i t}^{\mathrm{Post}}-C_{i t}\right)\left(1+r_{f, t+1}\right)+Y_{i t}
$$

with

$$
W_{i t}^{\mathrm{Post}}=W_{i t}-I\left(S_{i, t-1}=1\right)\left(F^{T F}+F^{T V} P_{t}^{s} N_{i, t-1}\right)
$$

$W_{i t}^{\text {Post }}$ denotes the amount of financial wealth available for investment or consumption after payment of the various costs. The term $I\left(S_{i, t-1}=1\right)\left(F^{T F}+F^{T V} P_{t}^{s} N_{i, t-1}\right)$ is the cost of exiting the stock market if the household participated in the previous period.

If the household decides to participate in the stock market its budget constraint is

$$
W_{i, t+1}=\left(W_{i t}^{\text {Post }}-C_{i t}\right)\left(1+r_{f, t+1}+\alpha_{i t}\left(r_{s, t+1}-r_{f, t+1}\right)\right)+Y_{i t}
$$

with

$$
\begin{aligned}
W_{i t}^{\text {Post }}= & W_{i t}-I\left(S_{i, t-1}=0\right)\left(F^{T F}+F^{T V} P_{t}^{s} N_{i t}\right) \\
& -I\left(N_{i t} \neq N_{i, t-1}, S_{i, t-1}=1\right)\left(F^{T F}+F^{T V} P_{t}^{s}\left|N_{i t}-N_{i, t-1}\right|\right)-F^{P} .
\end{aligned}
$$

The term $I\left(S_{i, t-1}=0\right)\left(F^{T F}+F^{T V} P_{t}^{s} N_{i t}\right)$ is the cost of entering the stock market if the household did not participate in the previous period. The term 
$I\left(N_{i t} \neq N_{i, t-1}, S_{i, t-1}=1\right)\left(F^{T F}+F^{T V} P_{t}^{s}\left|N_{i t}-N_{i, t-1}\right|\right)$ is the cost of trading for households who already participated in the previous period. The per period participation cost $F^{P}$ similarly represents a reduction in wealth.

The budget sets indicate that the policy function for the participation decision, $S_{i t}$, will depend on:

$S_{i, t-1}$ (with a positive sign) if $F^{T F}>0$. A positive fixed transactions cost works as an entry cost for current nonparticipants and as an exit cost for current participants. Both makes it more likely that households will not change their participation status between period $t-1$ and period $t$.

$P_{t}^{s} N_{i, t-1}$ (with a positive sign) if $F^{T V}>0$. The more stocks held at $t-1$, the more transactions costs $F^{T V} P_{t}^{s} N_{i, t-1}$ must be paid to exit the stock market. In the data I only observe each period's dollar stockholdings so I use $D_{i, t-1}=P_{t-1}^{s} N_{i, t-1}$ to proxy for $P_{t}^{s} N_{i, t-1}$. Since the portfolio observations in the PSID are 5 years apart and since households could have traded at any point in between, using $P_{t-1}^{s}$ may be as good an approximation to the 'typical' price faced during the period as $P_{t}^{s}$. To allow for a more flexible functional form, I also include the square of period $t-1$ dollar stockholdings.

I do not pursue implications about structural state dependence in the portfolio share for stocks conditional on entry. This is partly because such implications are harder to derive theoretically in the presence of all three costs considered here, and partly because the econometric framework for controlling for unobserved individual heterogeneity in the portfolio share to my knowledge is not developed.

In sum, by estimating a reduced form model of the participation decision $S_{i t}$ and determining if the lagged policy variables are significant and have the expected signs, it is possible to determine if the costs $F^{T F}$ and $F^{T V}$ are large enough to significantly affect stock market participation. The table below summarizes the predictions of structural state dependence in the policy function for the participation decision.

\begin{tabular}{|c|l|l|c|}
\hline Policy function & State variable & Significant if & Expected sign \\
\hline$S_{i t}$ & $S_{i, t-1}$ & $F^{T F}>0$ & + \\
\hline$S_{i t}$ & $D_{i, t-1}$ & $F^{T V}>0$ & + \\
\hline
\end{tabular}

Findings The coefficient on the lagged participation decision is positive and highly significant in the participation equation in both Table 3 and 4 implying that $F^{T F}>0$. Although I am not 
able to quantify the dollar amounts of these costs, their economic importance can be considered. The discrete change in the probability of being a stockholder in period $t$ caused by being a stockholder in period $t-1$ is 31.8 percentage points based on the results from Table 3.

If interaction terms of the education dummies and the lagged participation decision are included (not shown), they are generally insignificant. This indicates that the significance of education is more likely to reflect a correlation between education and preferences than between education and $F^{T F}$.

The coefficient on 1984 dollar stockholdings $D_{i, t-1}$ is also positive and significant in the probit model, whereas the coefficient on the squared 1984 dollar stockholdings is negative and significant. Based on the baseline results in Table 3, higher $D_{i, t-1}$ increases the probability of being a stockholder except in a range above the 98th percentile of $D_{i, t-1}$ (with the percentile calculated with in the set of 1984 stockholders only). A similar conclusion is reached if higher order terms of $D_{i, t-1}$ are included. For 1984 stockholders, an increase in 1984 dollars stockholdings from the 20th percentile (1239 dollars in 1983 prices) to the 80th percentile (24548 dollars) increases the probability of being a stockholder in 1989 by 11.9 percentage points evaluated at the mean of the other regressors, calculated for 1984 stockholders only. This suggests a economically important effect of $F^{T V}$, but this effect is only about a quarter as large and not statistically significant when accounting for unobserved individual effects as done in the following subsection.

Accounting for individual effects In dynamic panel data models as the one considered here, unobserved individual effects can imply that lagged dependent variables spuriously look significant. If an unobserved individual effect that affects both $S_{i, t-1}$ (or $D_{i, t-1}$ ) and $S_{i t}$ enters the error term, then $S_{i, t-1}$ (or $D_{i, t-1}$ ) will spuriously look significant. For example, suppose that a variable which is a strong determinant of participation is not included in the model, and that this variable is correlated over time (risk aversion would be an example if it differs across households). Then it affects both $S_{i t}$ and $S_{i, t-1}$ which, if not accounted for, spuriously could make $S_{i, t-1}$ be significant. Thus we will wrongly conclude that there is evidence of structural state dependence. This is similar to why ordinary least squares is inconsistent in a linear model with a lagged dependent variable and autocorrelated error terms.

As a robustness check on the above results on structural state dependence I use the random effects estimator of Heckman (1981) to account for unobserved individual effects. The idea behind the estimator is intuitive. By accounting for the autocorrelation in the error terms caused by the individual effects, the inconsistency can be diminished. The estimator of Heckman (1981) 
is for dynamic probit models and must be amended to account for the lag of dollar stockholdings also included in the probit model. The details of the resulting estimator are in the appendix.

Table 7 shows the results of estimating the probit model using the generalized version of Heckmans estimator. The coefficient on $S_{i, t-1}$ is a bit larger than earlier and still significant, confirming that the the significance of $S_{i, t-1}$ in the earlier regressions is not due to unobserved individual effects. Thus there is still support for the type of structural state dependence in the participation equation motivated by $F^{T F}$. As for the coefficients on $D_{i, t-1}$ and $D_{i, t-1}^{2}$, they are now much smaller than before accounting for unobserved individual effects, and no longer significant. Thus $F^{T V}$ does not seem large enough to affect the participation decision using this more correct estimator.

\subsubsection{Trading probabilities and equity share range}

In this section I provide simple evidence on trading frequencies and the changes in equity shares over time as a supplementary approach to determine whether a fixed transaction cost is present.

Consider a setting with only fixed transactions costs. This will lead to an inaction region characterized by two trigger points $\bar{\alpha}$ and $\underline{\alpha}$ and two return points $\bar{\alpha}^{*}$ and $\underline{\alpha}^{*}$, with $\underline{\alpha}<\underline{\alpha}^{*}$ and $\bar{\alpha}^{*}<\bar{\alpha}$. Inside the region between $\bar{\alpha}$ and $\underline{\alpha}$ the household does not trade, while for $\alpha>\bar{\alpha}$ the household sells stock to decrease $\alpha$ to $\bar{\alpha}^{*}$ and for $\alpha<\underline{\alpha}$ it buys stock to increase $\alpha$ to $\underline{\alpha}^{*}$. The width of the inaction region will depend on the size of $F^{T F}$ as well as the household's financial wealth, the stock price process and the household's preferences. ${ }^{7,8}$ The prediction tested below is that households with larger inital financial wealth (all else equal) will have a narrower inaction region and will trade more frequently than others in order to keep $\alpha$ inside this region. Intuitively, a given change in $\alpha$ corresponds to a larger dollar amount traded the larger the household's financial wealth is. Since the fixed transactions cost by definition is unaffected by the amount traded, while the (dollar equivalent) benefit of rebalancing depends on the amount traded, households with more financial wealth will find it optimal to incur the fixed transactions cost more often and keep $\alpha$ in a narrower range. These predictions can be tested on the set of continuing stockholders i.e. those who were in the stock market both in year $t$ and in the next year for which portfolio data is available.

The PSID wealth supplements for 1989 and 1994 contain questions about whether the household bought and/or sold stocks during the past five years and dollar amounts for such purchases and sales. However, the data are suspected to be heavily influenced by recall bias in the form of 'forgotten trades'. ${ }^{9}$ I therefore use data on trades from the Consumer Expenditure Survey 
(CEX). Households in this data set are only asked for a one year recall of financial information making this data set less subject to recall bias.

The CEX is a US household survey designed mainly to gather detailed information on household consumption but which also contains information about income and asset holdings. I use CEX data covering the period 1982, first quarter to 1996, first quarter (I exclude the data from 1980-81 since these are believed to be of lower quality). In each quarter approximately 4500 households are interviewed. Each household is interviewed five times. Financial information is gathered in the fifth quarter only. Households are asked about current assets as well as about changes in their holdings and proceeds from purchases and sales during the past year. The CEX contains information about four categories of financial assets. Households are asked for their holdings of "stock, bonds, mutual funds and other such securities", "U.S. savings bonds", "savings accounts", and "checking accounts, brokerage accounts and other similar accounts". As is clear from these categories a perfect separation of assets into stocks and less risky assets is not possible. I will refer to the category "stock, bonds, mutual funds and other such securities" as risky assets. The idea being tested is then that transactions in any of these assets involve an important fixed transactions cost.

To focus the analysis on households who held risky assets both at the time of the fifth interview and a year earlier, it must be determined who held risky assets a year prior to the survey. Furthermore, financial wealth must be calculated at this date. Two additional types of CEX variables are used for these purposes. The first reports whether the household holds the same amount, more, or less of the asset category compared to a year ago. The second reports the dollar difference in the estimated market value of the asset category held by the household last month compared with the value of the asset category held a year ago (as of last month). I define a household as holding risky assets a year ago if it 1) reports holding the same amount of the asset as a year ago and holds a positive amount at the time of the question (the fifth interview) or 2) reports having lower holdings of the asset than a year ago, or 3) reports having had an increase its holdings of the asset but by a dollar amount less than the reported holdings at the time of the question. ${ }^{10}$ To define financial assets as of a year prior to the survey, I subtract the one year change in holdings from the current holdings of each financial asset category. Given the initial and current holdings for each category, the change in the share of the portfolio invested in stocks can also be calculated. I restrict the sample to households with valid responses for each of the variables used in these definitions (i.e. current holdings, the change in holdings over the year, and the indicator variable for increased/constant/decreased ownership) and for the risky 
asset category the variables concerning purchases and sales which will be used below.

My final sample consists of 6770 households who held risky assets both at the time of the survey and a year prior to that. I define a household as having bought risky assets if it has a positive response to the question "Purchase price of stocks, bonds or mutual funds including broker fees bought by CU in past 12 months". Similarly I define a households as having sold stocks if it reports positive proceeds from sales of the same assets.

Figure 4 shows the results on trading probabilities based on the CEX. The figure plots for each decile of real initial financial wealth (in 1983 dollars) the percentage of households who bought or sold risky assets. The probability of trading (buying and/or selling) is increasing in initial financial wealth, from 0.29 for the lowest financial wealth decile to 0.53 for the highest decile. This confirms the presence of fixed trading costs. The effects are statistically significant and robust to controlling for age, education, race and income. In three probit models of the probability of (a) buying, (b) selling, or (c) buying and/or selling (including age, age squared, three education dummies, and a dummy for the head of household being white, household income and income squared as controls) financial wealth is significant with a positive coefficient and a t-statistic between 6.4 and 8.7. Financial wealth squared is significant with a negative coefficient in all three probit models. Each of the three trading probabilities are increasing in financial wealth except in a range above the 98th percentile of financial wealth observations. Splitting the CEX sample in subperiods according to interview dates and constructing separate graphs for each subperiods did not suggest a tendency for the trading probability lines to move upward or become steeper over time. Thus there is no evidence that the fixed transactions cost has declined over time. This is consistent with an interpretation of the fixed transactions cost predominantly capturing time spent on the decision making and transaction, as opposed to the small per trade cost charged in brokerage transactions.

Consistent with the finding that households with higher financial wealth are more likely to trade than others, these households tend to keep the risky asset share in their portfolios in a narrower range. Figure 5 shows for each decile of real initial financial wealth the mean absolute value of the change in the risky asset share (i.e. the mean of $\left|\alpha_{i, t}-\alpha_{i, t-1}\right|$ ). Over a one year period the portfolio share for those in the lowest financial wealth decile changed by about 0.14 (14 percentage points), compared to only about 0.05 for the highest financial wealth decile.

In sum, the CEX data suggest that fixed transactions costs are important. Households with higher financial wealth are more likely to trade than others and keep the share of risky assets in their portfolio in a narrower range than others. 


\subsection{Per period participation costs}

Unlike the fixed and variable transactions costs, the per period participation cost $F^{P}$ does not lead to structural state dependence in a household's portfolio choice. To determine the importance of $F^{P}$ this section takes the following approach. I first estimate how large a value of $F^{P}$ is needed for participation costs to explain the majority of nonparticipants' choices not to participate in the stock market. This assumes that all nonparticipating households face the same value of $F^{P}$. I then allow $F^{P}$ to differ across households and estimate its crosssectional distribution. The advantage of allowing heterogeneity in $F^{P}$ is that it enables the framework to explain different participation choices of households with similar wealth and other observable characteristics. Both estimations are based on estimating the benefits of stock market participation for each household. The underlying derivations assume that transactions costs $\left(F^{T V}\right.$ and $\left.F^{T F}\right)$ are absent. I then return to the affect transactions costs may have on the conclusions reached.

\subsubsection{Theoretical framework}

My approach to estimating the benefits of stock market participation relies on the definition of the certainty equivalent return to a portfolio. Start by considering a one period setting with utility defined over end of period wealth and with no nonfinancial income. Consider a portfolio with stochastic net return $r$. If household $i$ invests an amount $W_{i}$ in the portfolio at the beginning of the period, end of period wealth is $W_{i}(1+r)$. The certainty equivalent end of period wealth $W_{i}^{c e}$ is given by ${ }^{11}$

$$
E U\left(W_{i}(1+r)\right)=U\left(W_{i}^{c e}\right)
$$

Correspondingly, the certainty equivalent return to the portfolio can be defined as

$$
E U\left(W_{i}(1+r)\right)=U\left(W_{i}\left(1+r_{i}^{c e}\right)\right)
$$

with the interpretation that the investor is indifferent between investing $W_{i}$ in the risky portfolio with stochastic return $r$ and investing it in a riskless portfolio with return $r_{i}^{c e}$. In a setting with participation costs of investing in the risky portfolio, initial wealth is replaced by $W_{i}^{\text {Post }}=$ $W_{i}-F^{P}$. This wealth level then enters on the right hand side of the equation as well:

$$
E U\left(W_{i}^{\text {Post }}(1+r)\right)=U\left(W_{i}^{\text {Post }}\left(1+r_{i}^{c e}\right)\right)
$$


If the risky portfolio consists of stocks and riskless assets in the fractions $\alpha_{i}$ and $1-\alpha_{i}$, the above equation says that

$$
E U\left(W_{i}^{\mathrm{Post}}\left(1+r_{f}+\alpha_{i}\left(r_{s}-r_{f}\right)\right)\right)=U\left(W_{i}^{\mathrm{Post}}\left(1+r_{i}^{c e}\right)\right)
$$

where $r_{s}$ is the stock return and $r_{f}$ the riskless rate. Since the only risk in the portfolio of stocks and riskless assets stems from stocks, the certainty equivalent return to stocks can be defined by the equation

$$
E U\left(W_{i}^{\text {Post }}\left(1+r_{f}+\alpha_{i}\left(r_{s}-r_{f}\right)\right)\right)=U\left(W_{i}^{\text {Post }}\left(1+r_{f}+\alpha_{i}\left(r_{s, i}^{c e}-r_{f}\right)\right)\right) .
$$

This states that the investor is indifferent between investing fractions $\alpha_{i}$ and $1-\alpha_{i}$ in a portfolio of stocks and riskless bonds and investing all of $W_{i}^{\text {Post }}$ in a riskless asset with return $r_{f}+\alpha_{i}\left(r_{s, i}^{c e}-r_{f}\right)$. Thus $r_{s, i}^{c e}$ depends on $\alpha_{i}$. For those households who participate in the stock market, their choice of $\alpha_{i}$ will provide information about $r_{s, i}^{c e}$. In particular, if the household is risk averse then $r_{i}^{c e}$ is a number smaller than the expected net return on the risky portfolio $E\left(r_{f}+\alpha_{i}\left(r_{s}-r_{f}\right)\right)$. Therefore, if $\alpha_{i} \leq 1, r_{s, i}^{c e}<E\left(r_{s}\right) .{ }^{12}$ A household choosing $\alpha_{i}>0$ furthermore reveals that $r_{s, i}^{c e}>r_{f}$.

Consider now the more realistic case where households live for multiple periods and have nonfinancial income. In that case, we can define the certainty equivalent stock return $r_{s, i, t+1}^{c e}$ by the equation

$$
\begin{aligned}
& \max _{C_{i t}}\left\{U\left(C_{i t}\right)+\beta E V_{t}\left(\left(W_{i t}^{\text {Post }}-C_{i t}\right)\left(1+r_{f, t+1}+\alpha_{i t}\left(r_{s, t+1}-r_{f, t+1}\right)\right)+Y_{i t}\right)\right\} \\
= & \max _{C_{i t}}\left\{U\left(C_{i t}\right)+\beta E V_{t}\left(\left(W_{i t}^{\text {Post }}-C_{i t}\right)\left(1+r_{f, t+1}+\alpha_{i t}\left(r_{s, i, t+1}^{c e}-r_{f, t+1}\right)\right)+Y_{i t}\right)\right\} .
\end{aligned}
$$

where $V_{t}\left(W_{i, t+1}\right)$ denotes the value function defined over date $t+1$ wealth and $\beta$ is the discount factor. On the left side of this equation, the expectation is taken over $r_{s, t+1}$ and $Y_{i t}$. On the right side it is taken over $Y_{i t}$ only since $r_{s, i, t+1}^{c e}$ is nonstochastic. Again, $0<\alpha_{i t} \leq 1$ reveals that $r_{f, t+1}<r_{s, i, t+1}^{c e}<E\left(r_{s, t+1}\right)$. In the above definition, consumption in period $t$ is allowed to differ depending on whether the risky portfolio or the riskless portfolio is held. However, below I will need to assume that the chosen consumption for period $t$ (but not for future periods) is approximately unaffected by the portfolio choice.

The certainty equivalent stock return can now be used to determine the value of participating in the stock market. Given the definition of $r_{s, i, t+1}^{c e}$, the household will choose to participate in the stock market in the current period iff

$$
\begin{aligned}
& \max _{C_{i t}}\left\{U\left(C_{i t}\right)+\beta E V_{t}\left(\left(W_{i t}^{\text {Post }}-C_{i t}\right)\left(1+r_{f, t+1}+\alpha_{i t}\left(r_{s, i, t+1}^{c e}-r_{f, t+1}\right)\right)+Y_{i t}\right)\right\} \\
> & \max _{C_{i t}}\left\{U\left(C_{i t}\right)+\beta E V_{t}\left(\left(W_{i t}-C_{i t}\right)\left(1+r_{f, t+1}\right)+Y_{i t}\right)\right\} .
\end{aligned}
$$


where as earlier $W_{i t}^{\text {Post }}=W_{i t}-F^{P}$.

Below I consider two estimations. The first, estimation A, estimates the per period cost sufficient to explain the choices of a given percentage of nonparticipants. The second more ambitious part, estimation B, estimates the distribution of participation costs in the population. Estimation A: Homogeneous $F^{P}$

Consider a nonstockholding household for which $S_{i, t-1}=0$. From (20) above it follows that the period $t$ (gross) benefit of stock market participation is

$$
\text { Benefit }_{i t}=\left(W_{i t}^{\mathrm{Post}}-C_{i t}\right) \alpha_{i t}\left(r_{s, i, t+1}^{c e}-r_{f, t+1}\right)
$$

under the simplifying assumption that period $t$ consumption (but not future consumption) is unaffected by whether the household decides to enter the stock market or not.

On the cost side, the per period cost of stock market participation that could be avoided in period $t$ by not entering, or entering in a subsequent period, is

$$
\text { Avoidable } \text { cost }_{i t}=F^{P} \text {. }
$$

A value of $F^{P}$ greater or equal to Benefit $i t$ is sufficient to deter the household from participating in this period. A lower value will also be sufficient if there are transactions costs $\left(F^{T V}>0\right.$ or $\left.F^{T F}>0\right)$. This is the case since the household would need to be able to recover these additional costs either in this period or in future periods of stock market participation. In other words, if $x$ percent of nonparticipants have benefits less than $y$ dollars in period $t$, then it is conservative to say that a per period cost of $F^{P}=y$ is sufficient to explain the nonparticipation of $x$ percent of nonparticipants.

Under an additional assumption one can be more precise.

Assumption A: The per period benefits of stock market participation for observed nonparticipants are approximately the same across time periods for a given household $i$.

Most importantly, this assumes approximately constant holdings of financial wealth across periods for this group. ${ }^{13}$ Then the entry condition states that the household should participate iff

$$
\text { Benefit }_{i t}>F^{P}
$$

+Annuity value of all stock market transactions costs for household $i$. (24)

I will refer to the right hand side as the 'total participation cost', $F_{i}^{\text {Total }} .{ }^{14}$ The transactions costs involved consist of $F^{T F}$ paid at least twice, and $F^{T V}$ percent of traded values paid twice. The 
annuity value is calculated over years of stock market participation. Under Assumption A that per period benefits of stock market participation for observed nonparticipants is approximately the same in each period $t$, the interpretation is then as follows: An annualized value of all stock market participation costs of $y$ dollars is sufficient to explain the nonparticipation of $x$ percent of nonparticipants.

\section{Estimation B: Heterogeneous $F^{P}$}

Suppose now that $F^{P}$ is allowed to differ across households and time. This improves the models' ability to explain different choices by households with similar observable characteristics. For now, assume again that $F^{T V}=F^{T F}=0$. I return to the effects of transactions costs on this estimation below.

Given the definition of the benefit of stock market participation in (22) above, a simple approach to estimating the cross-sectional distribution of $F^{P}$ at date $t$ is as follows. Suppose that $\alpha_{i t}=\alpha_{t}$ for all $i$, that $r_{s, i, t+1}^{c e}-r_{f, t+1}=0.04 \forall i$, and that $F_{i t}^{P}$ is uncorrelated with financial wealth in the cross-section of households. Given these assumptions, the stock market participation condition states that household $i$ should participate in period $t$ iff

$$
\left(W_{i t}^{\text {Post }}-C_{i t}\right) \alpha_{t} 0.04>F_{i t}^{P}
$$

This condition is similar to the condition used by Mulligan and Sala-i-Martin (2000) in the context of the demand for interest bearing assets more generally.

Since the incentive to participate is linear in financial wealth, one can estimate the cross sectional distribution of $F_{i t}^{P}$ directly from the wealth distribution at date $t$. A simple nonparametric approach consists of calculating the percentage of households of different wealth who participate in the stock market. For example, if 27 percent of households with a financial wealth of $\$ 10000$ participates, then 27 percent of these households must have had participation cost below $10000 * 0.04=\$ 400$. Given assumption that $F_{i t}^{P}$ is cross-sectionally uncorrelated with $W_{i t}$, this implies that 27 percent of all households must have had participation costs below $\$ 400$. By splitting the sample into 10 wealth deciles and using this approach for each decile, one obtains 10 estimates of points on the cumulative distribution function for the cross sectional distribution of $F_{i t}^{P}$.

How will the presence of transactions costs affect this estimation? Transactions costs imply that stock market participation status becomes a state variable in the household's value function. This is the case since participating today affects the choices available tomorrow given the transactions costs. In the example above where 27 percent of those with approximately 
$\$ 10,000$ in financial wealth were stock market participants, one can no longer be sure that this implies that 27 percent of the draws of $F_{i t}^{P}$ are below $\$ 400$. At date $t$ households can be split into four groups according to their participation choices at $t-1$ and $t:\left(S_{i, t-1}=0, S_{i t}=0\right)$, $\left(S_{i, t-1}=0, S_{i t}=1\right),\left(S_{i, t-1}=1, S_{i t}=0\right),\left(S_{i, t-1}=1, S_{i t}=1\right)$. We would like to determine how many percent of the draws of $F_{i t}^{P}$ are less than $\$ 400$. The group $\left(S_{i, t-1}=0, S_{i t}=1\right)$ poses no difficulties. We can be sure that their $F_{i t}^{P}$ draw is less than $\$ 400$ (since their choice reveals that the period $t$ benefit exceeds $F^{P}$ plus any transactions costs that must be covered by the period t benefits for entry to have been worthwhile). Similarly with the group $\left(S_{i, t-1}=1\right.$, $\left.S_{i t}=0\right)$. We can be sure that their $F_{i t}^{P}$ draw is above $\$ 400$ since they have revealed that $F_{i t}^{P}$ exceeds their current period benefit of $\$ 400$ plus any future transactions cost they may save by staying in the market during this period..$^{15}$ The possibile misclassifications arise for the groups choosing $\left(S_{i, t-1}=0, S_{i t}=0\right)$ or $\left(S_{i, t-1}=1, S_{i t}=1\right)$. Those choosing $\left(S_{i, t-1}=0, S_{i t}=0\right)$ only reveal that $\$ 400$ is not sufficient to cover $F_{i t}^{P}$ plus any part of the transactions costs that must be covered by a period $t$ gain in order for entry to have been optimal. Thus they reveal $F_{i t}^{P} \geq \$ 400-z_{i t}^{00}$ for some positive value $z_{i t}^{00}$. Using the approach outlined above and classifying them all as having $F_{i t}^{P} \geq \$ 400$ leads one to overestimate the deciles of the cost distribution. However, those choosing $\left(S_{i, t-1}=1, S_{i t}=1\right)$ lead to a counterbalancing bias: They only reveal that $\$ 400$ plus any future transactions cost they save by staying in the market during this period exceeds $F_{i t}^{P}$, i.e. that $F_{i t}^{P} \leq \$ 400+z_{i t}^{11}$ for some positive value $z_{i t}^{11}$. Thus classifying them all as having $F_{i t}^{P} \leq \$ 400$ leads one to underestimate the deciles of the cost distribution. Overall, if equally many of the $\left(S_{i, t-1}=0, S_{i t}=0\right)$ households and the $\left(S_{i, t-1}=1, S_{i t}=1\right)$ households are misclassified, then the approach outlined assuming the absence of transactions costs will lead to an unbiased estimate of the cross-sectional distribution of $F_{i t}^{P}$. While both types of misclassification are increasing in the size of the transactions costs it is difficult to evaluate whether they are likely to cancel out. This should be kept in mind when interpreting the cost distribution estimates below.

In both estimation $\mathrm{A}$ and $\mathrm{B}$ one can allow for heterogeneity in $\alpha_{i t}$ across households (and time). Nonparticipants may have chosen to stay out of the market due to a low optimal stock share conditional on participation. However, accounting for heterogeneity based on a sample selection model has only small effects on the results and for simplicity is therefore omitted in the results shown below. Essentially, the main 'success' in terms of fit in the sample selection models above is in the participation equation (with a pseudo $R^{2}$ of 0.26 in Table 3 ). The fit in the equation for the proportion of financial wealth invested in stocks is comparatively poor (with the 
labor income variables the only ones that consistently come in significant). With transactions costs the poorer fit in the equation for the proportion invested in stocks is understandable since many households may have a portfolio share for stocks that differ from their (no transactions cost) optimum.

\subsubsection{Findings}

\section{Estimation A:}

To implement the above approach I make two additional assumptions. First, I calculate the benefit of stock market participation as $W_{i t} \alpha_{t}\left(r_{s, i, t+1}^{c e}-r_{f, t+1}\right)$ rather than $\left(W_{i t}^{\text {Post }}-C_{i t}\right) \alpha_{t}\left(r_{s, i, t+1}^{c e}-r_{f, t+1}\right)$. This overstates the benefits both by assuming that no wealth must be set aside for current period consumption and by replacing $W_{i t}^{\text {Post }}$ (wealth after entry and participation costs) by observed financial wealth. Second, I assume a value of $r_{s, i, t+1}^{c e}-r_{f, t+1}$ of 0.04. With an equity premium around 7 percent and a tax rate of e.g. 20 percentage points, the after tax equity return will be 5.6 percent. ${ }^{16}$ Since the certainty equivalent excess return on stocks is risk adjusted, 4 percent seems, if anything, to be a high value. Thus both these assumptions are conservative in that they most likely overstate the benefits of stock market participation and thus the costs needed to explain nonparticipation. As for the values of $\alpha_{i t} \mathrm{I}$ assume that each nonparticipant would have had a value of $\alpha_{i t}$ equal to the fraction of stock market wealth in total financial wealth of the sample for year $t$, should they have decided to enter. The fraction of stock market wealth in total financial wealth in the full PSID sample (as described in Table 1) is 24.1 percent in 1984, 35.9 percent in 1989 and 56.6 percent in 1994. Having calculated the period $t$ benefit of stock market participation for each of the nonparticipants as $\alpha_{t} W_{i t} 0.04$, I calculate the percentiles of the cross-sectional distribution of this benefit in the set of nonparticipants. Figure 6 illustrates these percentiles and thus gives the minimum dollar amount necessary to explain the choices of various percentages of nonparticipants.

The curve labelled '1989' shows the percentiles of the benefit distribution for those who were nonstockholders in 1989 (and in 1984 to be reasonably confident that the household did not participate in earlier periods). The benefits are calculated based on the households' 1989 financial wealth. Similarly the curve labelled '1994' is based on those who were nonparticipants in 1994 and 1989. For readability the figure leaves out percentiles above the 95th percentile.

In both 1989 and 1994 half of nonparticipants had estimated real annual stock market participation benefits of less than 30 dollars. The price index used to calculate the real values (the CPI for all urban consumers, all items) has basis value one on average over the years 1982-84. 
Multiply dollar values in the figure by 1.722 to get them in year 2000 dollars. Thus a per period stock market participation cost (or a total participation cost under assumption A) of around 50 dollars in year 2000 prices, is enough to explain the nonparticipation of half the nonparticipants. This reflects the fact that these households had little or no financial wealth to invest. Of the nonparticipants in 1989 (and 1984) around 21 percent had no financial wealth. Of the nonparticipants in 1994 (and 1989) about 29 percent had no financial wealth. Interpreting the per period participation cost as the cost of additional time spent following the market and doing more complicated taxes, a cost of 50 dollars translates into only 5 hours at an hourly wage of 10 dollars per hour. For both 1989 and 1994 a cost of 150 dollars per year (about 260 dollars in 2000 prices) is enough to explain the choices of 75 percent of nonparticipants. Thus while it is not reasonable to claim that participation costs can reconcile the choices of all nonparticipants, modest costs are sufficient to understand the choices of a large part of these households.

\section{Estimation B:}

The result is shown in Figure 7 for the sample of all households with positive financial wealth and again assuming that $\alpha_{i t}$ for each household equals the fraction of stock market wealth in total financial wealth of the sample for year $t$. Households with no financial wealth provide no information about the participation cost in this approach since the benefit of stock market entry is zero assuming they cannot borrow to invest in the stock market. The median per period participation cost is around $\$ 350$ (real 1982-84 dollars) for each year. The increase in participation for higher wealth deciles indicate some tendency for the top part of the cost distribution to decline over time. If one alternatively assumes a constant value of $\alpha_{i t}$ for each year, the median cost estimate also declines over time further suggesting decreased participation cost.

Since even among very rich households not all hold stocks, the estimated CDF does not reach one at any wealth level (the point corresponding to the last wealth decile is not included in the graph but is also far below one). This emphasizes the advantage of using a nonparametric approach, since a parametric approach would impose the requirement that the CDF indeed reaches one. The economic implication is that participation costs are unlikely to be the explanation for nonparticipation among high wealth households. More generally, if at each wealth level some of the nonparticipant have chosen not to hold stocks for reasons other than participation costs, my estimated CDF of the cost distribution will be shifted down/right compared to the true CDF. 


\section{Conclusion}

This paper has focused on four facts characterizing US households' portfolio choice: nonparticipation in the stock market by many households, large amounts of entry and exit over time, substantial cross-sectional heterogeneity in the portfolio share for stocks conditional on participation, and large changes in these portfolio shares over time for many continuing participants.

I have focused on the role for various stock market participation costs as well as nonfinancial income to help explain these facts. I find strong support for the presence of a fixed transactions cost of stock market trading using several tests, but no support for the importance of variable transactions costs. A fairly small per period costs of just 50 dollars in year 2000 prices, is found to be enough to explain the nonparticipation of half the nonparticipants, suggesting per period costs as a simple explanation for many households choice to stay out of the stock market.

As for nonfinancial income, I find clear evidence of a positive mean effect and a negative risk effect of nonfinancial income on the probability of being a stockholder and on the proportion of financial wealth invested in stocks conditional on participation. It has been argued that the nonparticipation phenomenon should be considered part of the solution to the equity premium puzzle because the consumption growth of nonstockholders covaries substantially less with the stock return than the consumption growth of stockholders (see Mankiw and Zeldes (1991), Vissing-Jorgensen (2002), Attanasio, Banks and Tanner (2002)). This indicates that the primary reason for nonparticipation is not that nonstockholders are faced with nonfinancial income which is highly correlated with stock market returns. Consistent with this I find no effect of the correlation of nonfinancial income with the stock market index on stock market participation or the proportion of financial wealth invested in stocks conditional on participation.

Overall, the results suggest that participation costs/transactions costs and nonfinancial income contribute substantially to understand observed heterogeneity in portfolio choices across households and over time. The analysis of the present paper of the nature and size of costs of stock market participation has parallels to the literature on investment under adjustment costs. Caballero, Engel and Haltiwanger (1995) emphasize how an average adjustment rate function which is increasing in mandated investments can give rise to time-varying sensitivity of aggregate investment to aggregate shocks. In a similar way, the sensitivity of the stock price to e.g. a shock to nonfinancial income in a situation with costs of stock market participation, is likely to differ depending of the cross-sectional distribution of households along the state variables. The number of household who chose to enter the stock market or to change the number of stocks held in response to a shock to nonfinancial income, will depend on how many households are close 
to the point where it becomes worthwhile to adjust. Developing these parallels may contribute towards understanding issues regarding time varying stock market liquidity and trading volume. 


\section{Appendix A. Likelihood function for dynamic probit model with correction for unobserved individual effects}

This appendix outlines how to estimate a dynamic probit model for stock market participation using two portfolio choice observations per household and accounting for unobserved individual effects. The approach generalizes the random effects dynamic probit estimator of Heckman (1981) to allow for a lagged dollar stockholdings as regressors.

In general, if the initial conditions of the discrete choice process could be assumed truly exogenous, or the process could be assumed to be in equilibrium, consistent estimates of the parameters could be obtained using maximum likelihood estimation. In most cases, neither of these assumptions are plausible. If so, one could consider a fixed effects approach. This however, only leads to consistent estimates as $T \rightarrow \infty$. In short samples, the bias of the fixed effects estimator can be very large as shown in Heckman (1981). Heckman instead proposes an approximate random effects estimator which is still biased but much less so than the fixed effects estimator. This approximate random effects estimator assumes that the individual effects are uncorrelated with the regressors other than the lags. For the panel data probit model with one lag, Heckman's estimator can be used for $T=2$ or larger.

\subsection{Model}

Denote the two dates for which portfolio observations are available by date 0 and date 1 . The probit equation for stock market participation at date 1 is as follows

$$
\begin{aligned}
& S_{i 1}^{*}=x_{i 1}^{\prime} \beta_{1}+\delta_{1} S_{i 0}+\delta_{2} D_{i 0}+\delta_{3} D_{i 0}^{2}+\nu_{i 1} \\
& S_{i 1}=\left\{\begin{array}{c}
1 \text { if } S_{i 1}^{*} \geq 0 \\
0 \text { otherwise }
\end{array}, \quad S_{i 0}=\left\{\begin{array}{c}
1 \text { if } S_{i 0}^{*} \geq 0 \\
0 \text { otherwise }
\end{array}\right.\right.
\end{aligned}
$$

where $S_{i 1}^{*}$ is the household's latent desire to participate in the stock market in period $1, S_{i 1}$ $\left(S_{i 0}\right)$ is a dummy variable equal to one if the household participates in period 1 (period 0 ), and $D_{i 0}$ is the dollar amount invested in stocks in period zero if any.

The following assumptions are made about $S_{i 0}^{*}$ and $D_{i 0}$ :

$$
\begin{gathered}
S_{i 0}^{*}=x_{i 0}^{\prime} \beta_{0}+\nu_{i 0} \\
D_{i 0}=w_{i 0}^{\prime} \gamma_{0}+u_{i 0}, \text { observed if } S_{i 0}=1 .
\end{gathered}
$$


The equation for $S_{i 0}^{*}$ is an approximation since the true model of the participation decision contains the lagged value of $S$ and $D$ as explanatory variables. However, the advantage of this approximation is that one can account for the individual effect simply by allowing for correlation between the error terms for a given individual over time. In my case period 0 is 1984 and period 1 is 1989. I include the same variables in $x$ and $w$ as in the previous Table 3 with one exception. With no lags in the probit model at date 0 , the date 0 system for $S_{i 0}^{*}$ and $D_{i 0}$ in (27), (28) will be identified based on functional form only if no variables are excluded. Since the education dummies were not significant in equity share equation in the earlier estimations for 1989, I therefore exclude them from $w_{0}$.

The error terms $\nu_{i 0}, \nu_{i 1}$, and $u_{i 0}$ include the unobserved individual effects and are therefore, in general, correlated. $\sigma_{\nu_{0}}^{2}$ and $\sigma_{\nu_{1}}^{2}$ are not identified and therefore each normalized to one. Finally, I assume that the three error terms $\nu_{i 0}, \nu_{i 1}$, and $u_{i 0}$ are joint normal conditional on $x_{i 0}$, $x_{i 1}$ and $w_{i 0}$ :

$$
\left[\begin{array}{c}
\nu_{i 0} \\
\nu_{i 1} \\
u_{i 0}
\end{array}\right] \mid x_{i 0}, x_{i 1}, w_{i 0} \sim N_{3}\left(\left[\begin{array}{l}
0 \\
0 \\
0
\end{array}\right],\left[\begin{array}{cc}
\Sigma_{11}^{a} & \Sigma_{12}^{a} \\
\Sigma_{21}^{a} & \Sigma_{22}^{a}
\end{array}\right]\right)
$$

where $\Sigma_{11}^{a}$ is $2 x 2, \Sigma_{22}^{a}$ is $1 x 1, \Sigma_{12}^{a}$ is $2 x 1$, and $\Sigma_{21}^{a}$ is $1 x 2$.

\subsection{Log-likelihood function}

The log-likelihood function is given by

$$
\log L=\Sigma_{i=1}^{N} \ln P\left(S_{i 0}, S_{i 1} \mid x_{i 0}, x_{i 1}, w_{i 0}\right)
$$

The assumption made above implies that

$$
\begin{gathered}
{\left[\begin{array}{c}
\nu_{i 0} \\
\nu_{i 1}
\end{array}\right] \mid u_{i 0}, x_{i 0}, x_{i 1}, w_{i 0} \sim N_{2}\left(\mu^{b}, \Sigma^{b}\right)} \\
\mu^{b}=\left[\begin{array}{l}
0 \\
0
\end{array}\right]+\Sigma_{12}^{a}\left(\Sigma_{22}^{a}\right)^{-1}\left(u_{i 0}-0\right), \Sigma^{b}=\Sigma_{11}-\Sigma_{12}^{a}\left(\Sigma_{22}^{a}\right)^{-1} \Sigma_{21}^{a} .
\end{gathered}
$$

For $S_{i 0}=0, S_{i 1}=0$ :

$$
\begin{aligned}
P\left(S_{i 0}, S_{i 1} \mid x_{i 0}, x_{i 1}, w_{i 0}\right) & =P\left(\nu_{i 0}<-x_{i 0}^{\prime} \beta_{0}, \nu_{i 1}<-x_{i 1}^{\prime} \beta_{1}-\delta_{1} S_{i 0}-\delta_{2} D_{i 0}-\delta_{3} D_{i 0}^{2} \mid x_{i 0}, x_{i 1}, w_{i 0}\right) \\
& =\Phi_{2}\left(-x_{i 0}^{\prime} \beta_{0},-x_{i 1}^{\prime} \beta_{1}-\delta_{1} S_{i 0}-\delta_{2} D_{i 0}-\delta_{3} D_{i 0}^{2}, \rho_{\nu_{0}, \nu_{1}}\right)
\end{aligned}
$$


where $\rho_{\nu_{0}, \nu_{1}}=\Sigma_{11}^{a}(2,1)$.

For $S_{i 0}=1, S_{i 1}=1$ :

$$
\begin{aligned}
& P\left(S_{i 0}, S_{i 1} \mid x_{i 0}, x_{i 1}, w_{i 0}\right) \\
= & P\left(\nu_{i 0} \geq-x_{i 0}^{\prime} \beta_{0}, \nu_{i 1} \geq-x_{i 1}^{\prime} \beta_{1}-\delta_{1} S_{i 0}-\delta_{2} D_{i 0}-\delta_{3} D_{i 0}^{2}, u_{i 0} \mid x_{i 0}, x_{i 1}, w_{i 0}\right) \\
= & P\left(\nu_{i 0} \geq-x_{i 0}^{\prime} \beta_{0}, \nu_{i 1} \geq-x_{i 1}^{\prime} \beta_{1}-\delta_{1} S_{i 0}-\delta_{2} D_{i 0}-\delta_{3} D_{i 0}^{2} \mid u_{i 0}, x_{i 0}, x_{i 1}, w_{i 0}\right) P\left(u_{i 0} \mid x_{i 0}, x_{i 1}, w_{i 0}\right) \\
= & P\left(\begin{array}{c}
\frac{\nu_{i 0}-\mu^{b}(1,1)}{\sqrt{\Sigma^{b}(1,1)}} \geq \frac{-x_{i 0}^{\prime} \beta_{0}-\mu^{b}(1,1)}{\sqrt{\Sigma^{b}(1,1)}}, \\
\frac{\nu_{i 1}-\mu^{b}(2,1)}{\sqrt{\Sigma^{b}(2,2)}} \geq \frac{-x_{i 1}^{\prime} \beta_{1}-\delta_{1} P_{i 0}-\delta_{2} D_{i 0}-\delta_{3} D_{i 0}^{2}-\mu^{b}(2,1)}{\sqrt{\Sigma^{b}(2,2)}} \mid u_{i 0}, x_{i 0}, x_{i 1}, w_{i 0}
\end{array}\right) P\left(u_{i 0} \mid x_{i 0}, x_{i 1}, w_{i 0}\right) \\
= & \Phi_{2}\left(k_{i 0}^{b}, k_{i 1}^{b}, \rho_{\nu_{0} \nu_{1}}^{b}\right) \frac{1}{\sqrt{2 \pi \sigma_{u_{0}}^{2}}} \exp \left\{-\frac{1}{2}\left(\frac{u_{i 0}}{\sigma_{u_{0}}}\right)^{2}\right\}
\end{aligned}
$$

where $k_{i 0}^{b}=\frac{x_{i 0}^{\prime} \beta_{0}+\mu^{b}(1,1)}{\sqrt{\Sigma^{b}(1,1)}}, k_{i 1}^{b}=\frac{x_{i 1}^{\prime} \beta_{1}+\delta_{1} S_{i 0}+\delta_{2} D_{i 0}+\delta_{3} D_{i 0}^{2}+\mu^{b}(2,1)}{\sqrt{\Sigma^{b}(2,2)}}, \rho_{\nu_{0} \nu_{1}}^{b}=\frac{\Sigma^{b}(2,1)}{\sqrt{\Sigma^{b}(1,1) \Sigma^{b}(2,2)}}, u_{i 0}=$ $\alpha_{i 0}-w_{i 0}^{\prime} \gamma_{0}$.

For $S_{i 0}=1, S_{i 1}=0$ :

$$
\begin{aligned}
& P\left(S_{i 0}, S_{i 1} \mid x_{i 0}, x_{i 1}, w_{i 0}\right) \\
& =P\left(\nu_{i 0} \geq-x_{i 0}^{\prime} \beta_{0}, \nu_{i 1}<-x_{i 1}^{\prime} \beta_{1}-\delta_{1} S_{i 0}-\delta_{2} D_{i 0}-\delta_{3} D_{i 0}^{2}, u_{i 0} \mid x_{i 0}, x_{i 1}, w_{i 0}\right) \\
& =P\left(\nu_{i 0} \geq-x_{i 0}^{\prime} \beta_{0}, \nu_{i 1}<-x_{i 1}^{\prime} \beta_{1}-\delta_{1} S_{i 0}-\delta_{2} D_{i 0}-\delta_{3} D_{i 0}^{2} \mid u_{i 0}, x_{i 0}, x_{i 1}\right) P\left(u_{i 0} \mid x_{i 0}, x_{i 1}, w_{i 0}\right) \\
& =P\left(\begin{array}{c}
\frac{\nu_{i 0}-\mu^{b}(1,1)}{\sqrt{\Sigma^{b}(1,1)}} \geq \frac{-x_{i 0}^{\prime} \beta-\mu^{b}(1,1)}{\sqrt{\Sigma^{b}(1,1)}}, \\
\frac{\nu_{i 1}-\mu^{b}(2,1)}{\sqrt{\Sigma^{b}(2,2)}}<\frac{-x_{i 1}^{\prime} \beta_{1}-\delta_{1} S_{i 0}-\delta_{2} D_{i 0}-\delta_{3} D_{i 0}^{2}-\mu^{b}(2,1)}{\sqrt{\Sigma^{b}(2,2)}} \mid u_{i 0}, x_{i 0}, x_{i 1}, w_{i 0}
\end{array}\right) P\left(u_{i 0} \mid x_{i 0}, x_{i 1}, w_{i 0}\right) \\
& =\Phi_{2}\left(k_{i 0}^{b},-k_{i 1}^{b},-\rho_{\nu_{0} \nu_{1}}^{b}\right) \frac{1}{\sqrt{2 \pi \sigma_{u_{0}}^{2}}} \exp \left\{-\frac{1}{2}\left(\frac{u_{i 0}}{\sigma_{u_{0}}}\right)^{2}\right\} \text {. }
\end{aligned}
$$

with $k_{i 0}^{b}, k_{i 1}^{b}, \rho_{\nu_{0} \nu_{1}}^{b}$ and $u_{i 0}$ as above.

Finally, for $S_{i 0}=0, S_{i 1}=1$ :

$$
\begin{aligned}
P\left(S_{i 0}, S_{i 1} \mid x_{i 0}, x_{i 1}, w_{i 0}\right) & =P\left(\nu_{i 0}<-x_{i 0}^{\prime} \beta_{0}, \nu_{i 1} \geq-x_{i 1}^{\prime} \beta_{1}-\delta_{1} S_{i 0}-\delta_{2} D_{i 0}-\delta_{3} D_{i 0}^{2} \mid x_{i 0}, x_{i 1}, w_{i 0}\right) \\
& =\Phi_{2}\left(-x_{i 0}^{\prime} \beta_{0}, x_{i 1}^{\prime} \beta_{1}+\delta_{1} S_{i 0}+\delta_{2} D_{i 0}+\delta_{3} D_{i 0}^{2},-\rho_{\nu_{0}, \nu_{1}}\right) .
\end{aligned}
$$




\section{References}

[1] Alessie, R., S. Hochguertel, and A. van Soest, 1999, Household Portfolios in the Netherlands, book chapter in Household Portfolios, L. Guiso and T. Jappelli eds., Cambridge, MA, MIT Press.

[2] Amemiya, T., 1978, The Estimation of a Simultaneous Equation Generalized Probit Model, Econometrica, 46, 5, 1193-1205.

[3] Attanasio, O., J. Banks, and S. Tanner, 2002, Asset Holding and Consumption Volatility, forthcoming, Journal of Political Economy.

[4] Barsky, R. B., F. Thomas Juster, M. S. Kimball, and M. D. Shapiro, 1997, Preference Parameters and Behavioral Heterogeneity: An Experimental Approach in the Health and Retirement Study, Quarterly Journal of Economics, 2, 537-579.

[5] Bernheim, B. D. and D. M. Garrett, 2001, The Effects of Financial Education in the Workplace: Evidence from a Survey of Households, forthcoming Journal of Public Economics.

[6] Bernheim, B. D., D. M. Garrett, and D. M. Maki, 2001, Education and Saving: The LongTerm Effects of High School Financial Curriculum Mandates, Journal of Public Economics, $80,3,435-465$.

[7] Bertaut, C., 1998, Stockholding Behavior of U. S. Households: Evidence from the 1983-1989 Survey of Consumer Finances, Review of Economics and Statistics, 80, 2, 263-275.

[8] Borsch-Supan, A. and A. Eymann, 1999, Household Portfolios in Germany, book chapter in Household Portfolios, L. Guiso and T. Jappelli eds., Cambridge, MA, MIT Press.

[9] Caballero, R. J., E. M. R. A. Engel, and J. C. Haltiwanger, 1995, Plant-Level Adjustment and Aggregate Investment Dynamics, Brookings Papers on Economic Activity, 2, 1-54.

[10] Campbell, J. Y. and L. M. Viceira, 1996, Consumption and Portfolio Decisions When Expected Returns are Time Varying, Quarterly Journal of Economics, 2, 433-495.

[11] Carroll, C. D. and A. A. Samwick, 1997, The nature of precautionary wealth, Journal of Monetary Economics, 40, 41-71.

[12] Chiteji, N. S. and F. P. Stafford (2000), Asset Ownership Across Generations, Research Report No. 00-454, Population Studies Center at the Institute for Social Research, University of Michigan. 
[13] Cocco, J., F. Gomes, and P. Maenhout, 2001, "Consumption and Portfolio Choice Over the Life-Cycle", working paper, INSEAD and London Business School.

[14] Constantinides G.M. and D. Duffie, 1996, Asset pricing with Heterogeneous Consumers, Journal of Political Economy, 104, 219-240.

[15] Duflo, E. and E. Saez, 2000, Participation and Investment Decisions in a Retirement Plan: The Influence of Colleagues' Choices, forthcoming Journal of Public Economics.

[16] Elmendorf, D. W. and M. S. Kimball, 1998, Taxation of Labor Income and the Demand for Risky Assets, International Economic Review, 41, 3, 801-832.

[17] Gakidis, H. E., 1998, Stocks for the Old? Earnings Uncertainty and Life-Cycle Portfolio Choice, Ph. D. Thesis, MIT.

[18] Gollier, C. and J. W. Pratt, 1996, Risk vulnerability and the tempering effect of background risk, Econometrica, 64, 5, 1109-1123.

[19] Guiso, L., and T. Jappelli, 2002, Households' Portfolios in Italy, book chapter in Household Portfolios, L. Guiso and T. Jappelli eds., Cambridge, MA, MIT Press.

[20] Guiso, L., T. Jappelli, and D. Terlizzese, 1996, Income Risk, Borrowing Constraints, and Portfolio Choice, American Economic Review, 86, 1, 158-172.

[21] Haliassos, M. and C. Bertaut, 1995, Why Do So Few Hold Etocks?, Economic Journal, 105, 1110-1129.

[22] Heaton, J. and D. Lucas, 1996, Evaluating the Effects of Incomplete Markets on Risk Sharing and Asset Pricing, Journal of Political Economy, 104, 3.

[23] Heaton, J. and D. Lucas, 2000, Portfolio Choice and Asset Prices: The Importance of Entrepreneurial Risk, Journal of Finance, LV, 3, 1163-1198.

[24] Heckman, J. J., 1981, The Incidental Parameters Problem and the Problem of Initial Condition in Estimating a Discrete Time-Discrete Data Stochastic Process, in C. F. Manski and D. McFadden, ed.: Structural Analysis of Discrete Data with Econometric Applications (MIT Press, Cambridge).

[25] Hong, H., J. D. Kubik, and J. C. Stein, 2001, Social Interaction and Stock-Market Participation, working paper, Stanford University. 
[26] Hurst, E., M. C. Luoh, and F. P. Stafford, The Wealth Dynamics of American Families, 1984-1994, Brookings Papers on Economic Activity, 1:1998, 267-337.

[27] Investment Company Institute, 1999, Equity Ownership in America.

[28] Jones, C. M., 2001, A Century of Stock Market Liquidity and Trading Costs, working paper, Columbia University.

[29] Lee, Lung-Fei, 1981, Simultaneous Equations Models with Discrete and Censored Dependent Variables, in C. F. Manski and D. McFadden, ed.: Structural Analysis of Discrete Data with Econometric Applications (MIT Press, Cambridge).

[30] Luttmer, E. G. J., 1999, What level of Fixed Costs Can Reconcile Asset Returns and Consumption Choices, Journal of Political Economy, 107, 5, 969-97

[31] Mankiw, N. G., 1986, The Equity Premium Puzzle and the Concentration of Aggregate Shocks, Journal of Financial Economics, 17, 211-219.

[32] Mankiw, N.G. and S. Zeldes, 1991, The consumption of Stockholders and NonStockholders, Journal of Financial Economics, 17, 211-219.

[33] Marshall, D. A. and N. G. Parekh, 1999, Can Costs of Consumption Adjustment Explain Asset Pricing Puzzles, Journal of Finance, 54, 2, 623-54.

[34] Merton, R. C., 1969, Lifetime Portfolio Selection Under Uncertainty: The Continuous-Time Case, Review of Economics and Statistics, 51, 247-257.

[35] Merton, R. C., 1971, Optimum Consumption and Portfolio Rules in a Continuous-Time Model, Journal of Economic Theory, 3, 373-413.

[36] Merton, R. C., 1992, Continuous-Time Finance, Blackwell Publishers, Cambridge, MA.

[37] Mulligan, C. and X. Sala-I-Martin, 2000, Extensive Margins and the Demand for Money at Low Interest Rates, Journal of Political Economy, 108, 5, 961-91.

[38] Paiella, M., 1999, Transaction Costs and Limited Stock Market Participation to Reconcile Asset Prices and Consumption Choices, working paper, University College London.

[39] Polkovnichenko, V., 2001, Limited Stock Market Participation and the Equity Premium, working paper, University of Minnesota. 
[40] Pratt, J. W., 1964, Risk aversion in the Small and the Large , Econometrica, 32, 122-136.

[41] Rea, J. D. and B. K. Reid, 1998, Trends in the Ownership Cost of Equity Mutual Funds, Investment Company Institute Perspective, 4, 3, November.

[42] Samuelson, P. A., 1969, Lifetime Portfolio Selection by Dynamic Stochastic Programming, Review of Economics and Statistics, 51, 3, 239-246.

[43] Storesletten, K., C. Telmer, and A. Yaron, 1998, Persistent Idiosyncratic Shocks and Incomplete Markets, working paper, Stockholm University.

[44] Viceira, L. M., 2001, Optimal Portfolio Choice for Long-Horizon Investors with Nontradable Labor Income, Journal of Finance, 56, 2, 433-470.

[45] Williams, N., 2000, Optimal Portfolios Under Transactions and Information Costs, working paper, University of Chicago.

[46] Vissing-Jorgensen, A., 2002, Limited Asset Market Participation and the Elasticity of Intertemporal Substitution, forthcoming, Journal of Political Economy. 


\section{Footnotes}

1. 'Structural state dependence' refers to a situation where individuals who have experienced an event in the past are more likely to experience that event in the future, as a consequence of the event affecting future preferences, prices, or constraints. In the present setting with participation/transactions costs the effects work through the budget constraints.

2. Several papers analyze the general equilibrium effects of uninsurable income risk on asset prices. See, for example, Mankiw (1986), Heaton and Lucas (1996), Constantinides and Duffie (1996), and Storesletten et al. (1998).

3. I define one-digit industry and occupation codes based on the three digit PSID codes as follows. The PSID codes are in parenthesis after the code I assigned.

Occupation: 0 (no occupation, or code 999), 1 (1-195), 2 (201-245, 801-802), 3 (260-285), 4 (301-395), 5 (401-600), 6 (601-695), 7 (701-715), 8 (740-785, 821-824), 9 (901-965, 980-984).

Industry: 0 (no industry, or code 999), 1 (17-28), 2 (47-57, 67-77), 3 (107-398), 4 (407-479), 5 (507-698), 6 (707-718), 7 (727-759), 8 (769-798), 9 (807-809, 828-897), 10 (907-937).

4. Industry and occupation dummies were also considered as instruments but specification tests reject them as valid instruments. A likely reason is that employees in certain industries and occupations are more likely to get company stock as part of their salary. This was confirmed based on data from the Survey of Consumer Finances in which separate information about company stock is available.

5. Given the information available, it is not possible to test if the fixed cost of trading is larger for first time buyers than others.

6. Even in the absence of costs of stock market participation, the theory on portfolio choice in the presence of nonfinancial income does not allow a closed form solution to be derived when nonfinancial income is risky (and less than perfectly correlated with a combination of asset returns) and/or investment opportunities vary over time. Progress has been made by Viceira (2001) and Campbell and Viceira (1999) using log-linearization, but the log-linearization constants remain complicated functions of the underlying parameters.

7. It is also likely to depend in the household's nonfinancial income process, although I do not know of any work considering such effects.

8. The nature of the optimal trading policy for participants is still characterized by two trigger points and two return points even if variable transactions costs are present in addition to the fixed transactions cost, see Williams (2000).

9. When using the questions about current stock holdings in the 1984, 1989, and 1994 data 
one obtains more stock market entrys and exits than is consistent with the data on purchases and sales. For example, many of those who held stocks in 1989 but not in 1984 did not report having purchased stock, and most of those who had stock in 1984 but not in 1989 did not report having sold stock. This is true even when considering households with no change in household composition and is not due to nonresponse or data imputation. Gifts and inheritances seem unlikely to account for the majority of the inconsistencies. In response to these likely recall bias problems the PSID will be fielding the wealth supplements every two years from 1999 onwards and furthermore has introduced event history calendars to help eliminate recall inconsistencies.

10. A small number of households report an increase in their holdings of stocks, bonds or mutual funds larger than the value of the reported end of period holdings. I set their initial stockholdings to zero. For interviews conducted from 1991 onwards, about 5 percent of households report stockholdings of $\$ 1$. These are likely to be coding errors (for example, many of these report having bought or sold substantial dollar amounts of stocks during the past year). Since it is not possible to correctly calculate initial financial wealth for these households they are dropped.

11. In the terminology of Pratt (1964) and the subsequent literature, $W_{i}^{c e}$ is given by $E\left(W_{i}(1+r)\right)-\pi_{i}$, where $\pi_{i}$ is the risk premium that makes the investor indifferent between receiving the stochastic amount $W_{i}(1+r)$ and the certain amount $E\left(W_{i}(1+r)\right)-\pi_{i}$.

12. If households can borrow at a rate lower than $E\left(r_{s}\right)$, it is is possible for $r_{s}^{c e}$ to exceed $E\left(r_{s}\right)$. Judging from data on margin investing this is unlikely to substantially affect my results. Less than 1 percent of households had margin loans at a brokerage house in the 1998 Survey of Consumer Finances, and the loans totalled less than 1 percent of the value of the stock market. The magnitude of borrowing for investment through other channels (e.g. by taking out a second home mortgage) is hard to estimate.

13. This assumption clearly would make less sense for participants since their benefits of participation are likely to change over time thus explaining their entry and future exit.

14. Note that unlike $F^{P}, F^{T V}$ and $F^{T F}$ which are exogenous parameters in the household's problem, the total participation cost has an endogenous element since the number of periods of stock market participation is chosen by the household.

15. For example, a household with a temporary increase in consumption needs may decide to run down only non-stock wealth in this period in order save the transactions costs involved in trading stocks.

16. The exact tax rate is difficult to calculate since some stockholdings are in pensions plans 
in which returns accumulate tax-free and are only taxed upon withdrawal. 


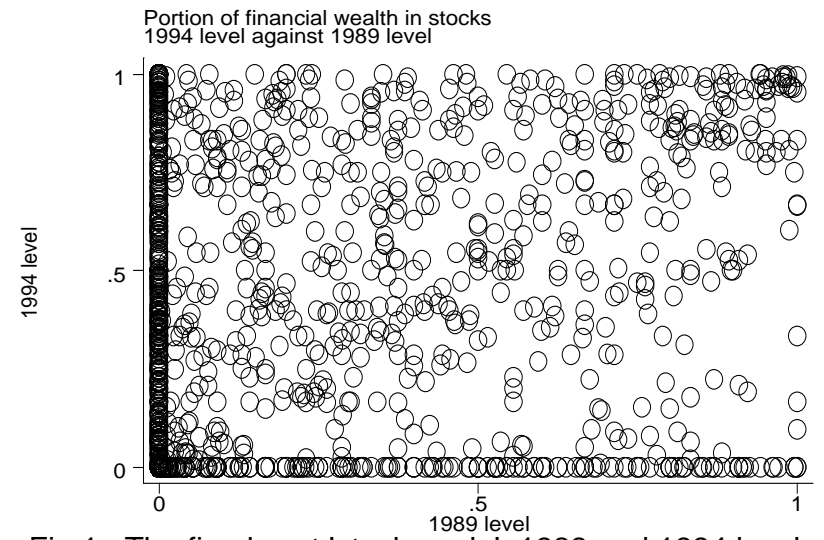

Fig.1a The fixed cost 'stock angle', 1989 and 1994 levels

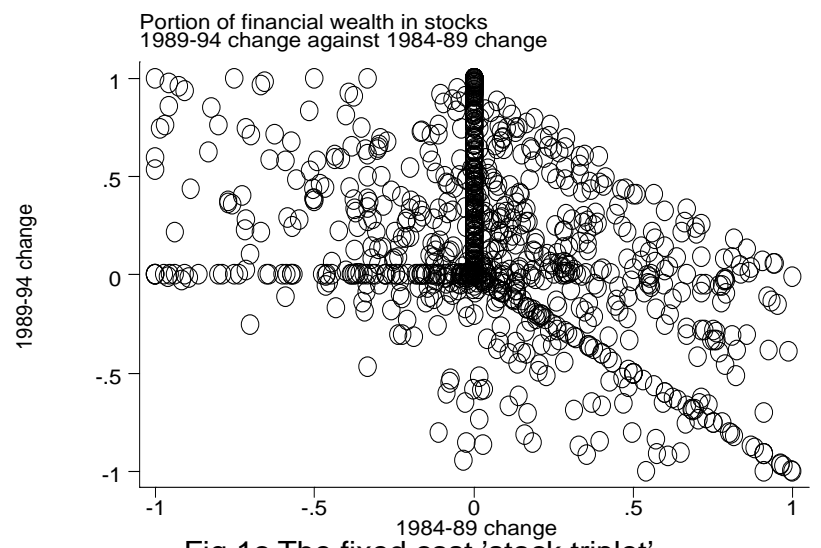

Fig.1c The fixed cost 'stock triplet'

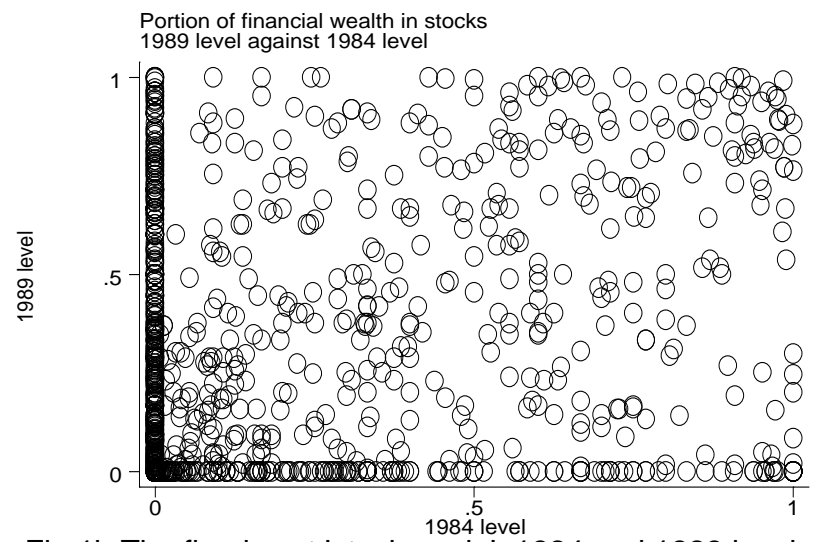

Fig.1b The fixed cost 'stock angle', 1984 and 1989 levels

Figure 1: The graphs illustrate the dynamics of the proportion of financial wealth invested in stocks for a panel of households. The data are from the 1984, 1989, and 1994 Wealth Supplements to the Panel Study of Income Dynamics (PSID). 'Stocks' refer to shares of stock in publicly held corporations, mutual funds, and investment trusts, including stocks in IRAs. Households with zero financial wealth are excluded. The terminology 'angle' refers to the L-shaped formation of point in Figures 1a,b. The points on the horizontal axis in these two figures correspond to households who left the stock market between the first and the second year for which data are plotted. The points on the vertical axis correspond to households who entered the stock market between the first and the second year for which data are plotted. 'Triplet' refers to the three 'lines' formed by points in Figure 1c. The downward sloping line of points in this figure correspond to households who entered the stock market between 1984 and 1989, but left the market between 1989 and 1994. 


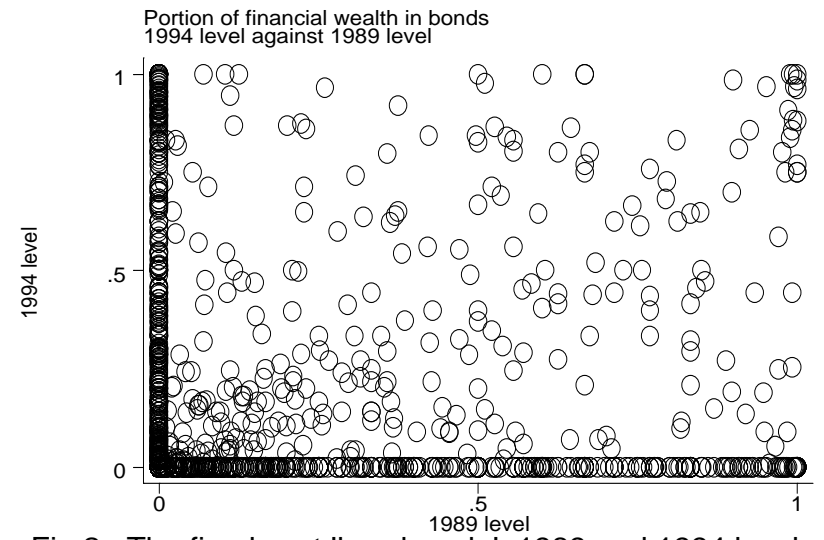

Fig.2a The fixed cost 'bond angle', 1989 and 1994 levels

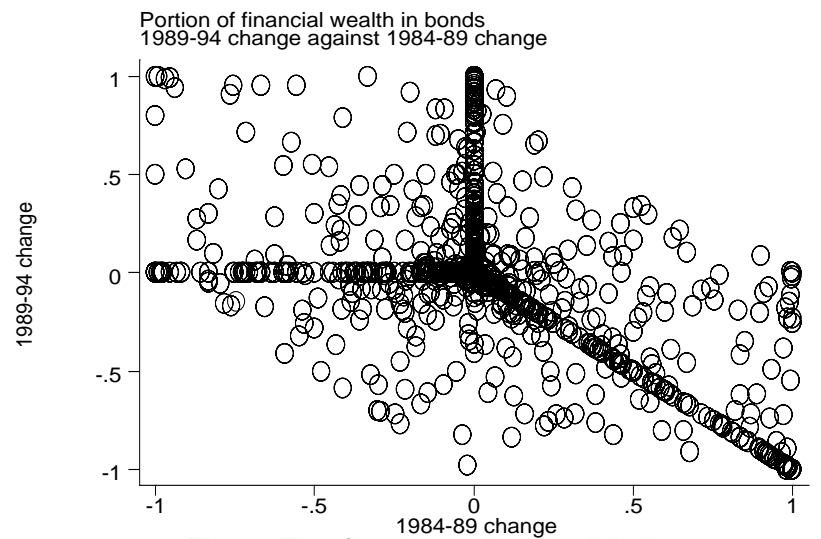

Fig.2c The fixed cost 'bond triplet'

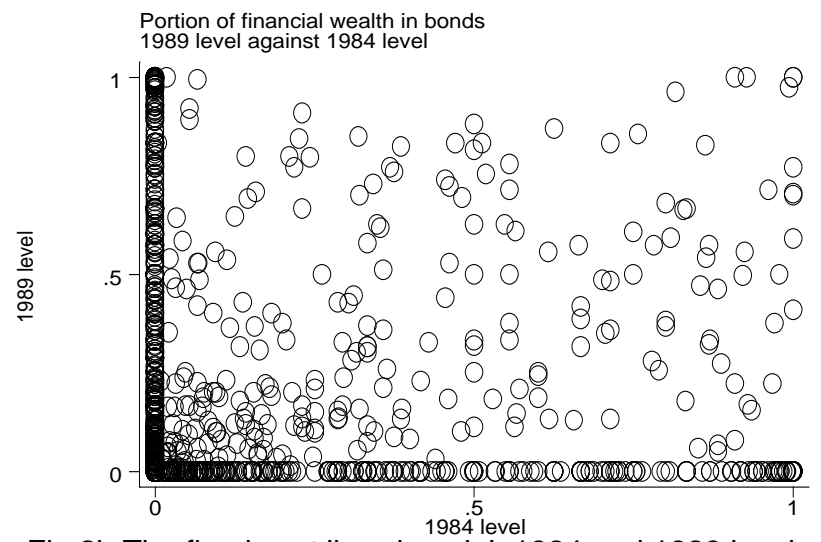

Fig.2b The fixed cost 'bond angle', 1984 and 1989 levels

Figure 2: The graphs illustrate the dynamics of the proportion of financial wealth invested in bonds for a panel of households. The data are from the 1984, 1989, and 1994 Wealth Supplements to the Panel Study of Income Dynamics (PSID). 'Bonds' refer to bond funds, cash value in life insurance policies, valuable collections for investment purposes, and rights in trusts and estates. Households with zero financial wealth are excluded. The terminology 'angle' refers to the Lshaped formation of point in Figures 2a,b. The points on the horizontal axis in these two figures correspond to households who left the bond market between the first and the second year for which data are plotted. The points on the vertical axis correspond to households who entered the bond market between the first and the second year for which data are plotted. 'Triplet' refers to the three 'lines' formed by points in Figure 2c. The downward sloping line of points in this figure correspond to households who entered the bond market between 1984 and 1989, but left the market between 1989 and 1994. 


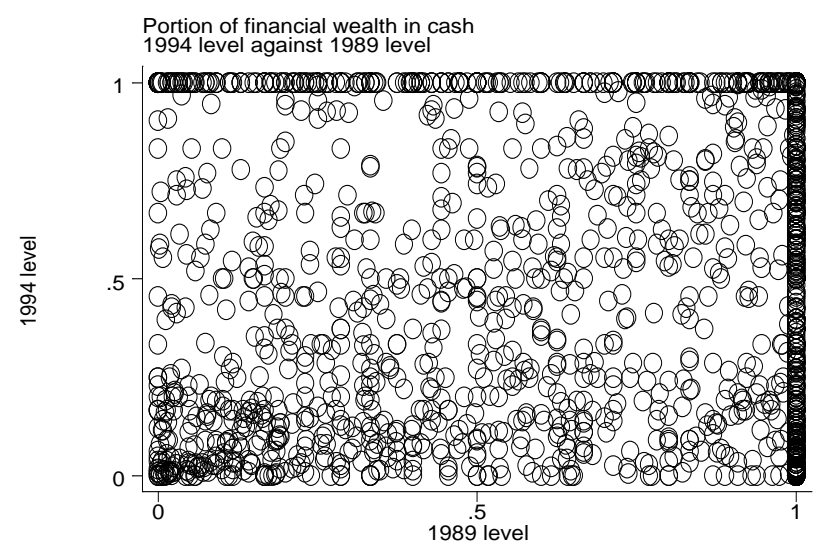

Fig.3a The fixed cost 'cash angle', 1989 and 1994 levels

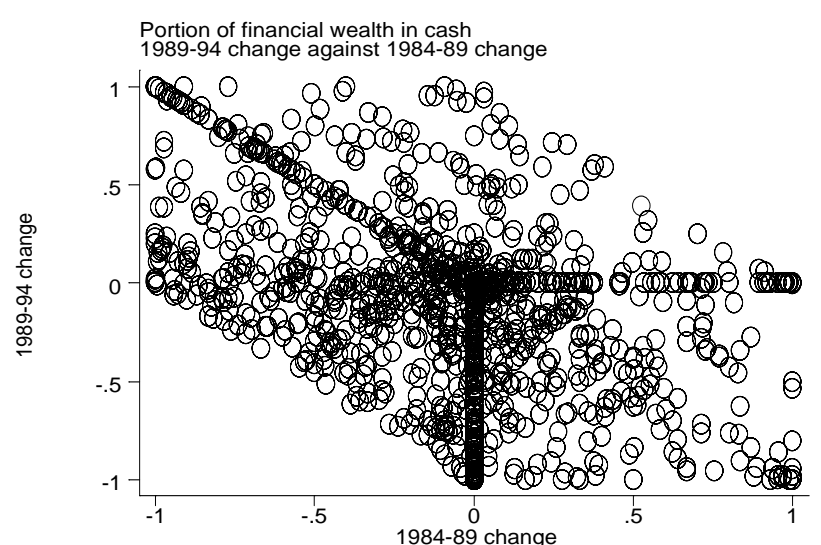

Fig.3c The fixed cost 'cash triplet'

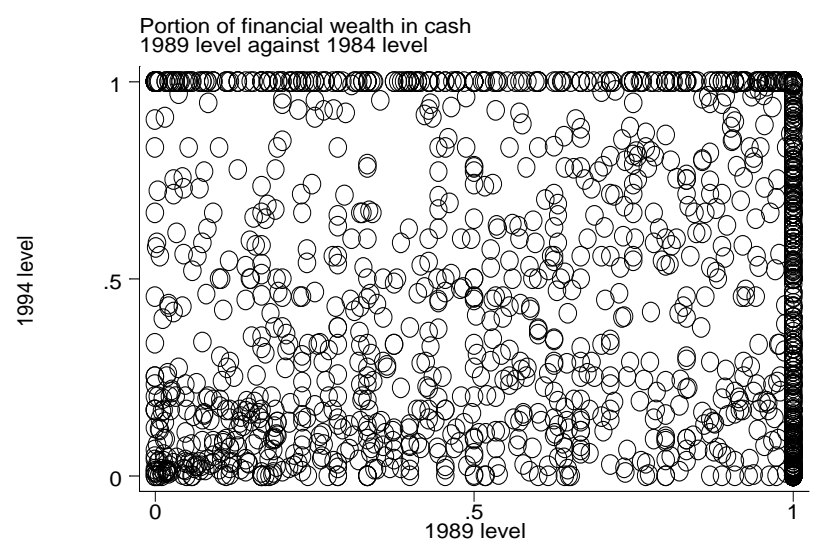

Fig.3b The fixed cost 'cash angle', 1984 and 1989 levels

Figure 3: The graphs illustrate the dynamics of the proportion of financial wealth invested in cash and other very liquid assets for a panel of households. The data are from the 1984, 1989, and 1994 Wealth Supplements to the Panel Study of Income Dynamics (PSID). 'Cash' refers to holdings in checking or savings accounts, money market bonds, or Treasury bills, including IRA's. Households with zero financial wealth are excluded. The terminology 'angle' refers to the (inverted) L-shaped formation of point in Figures 3a,b. The points on the horizontal axis in these two figures correspond to households who had all their financial wealth in cash in the second but not the first year plotted. The points on the vertical axis correspond to households who had all their financial wealth in cash in the first but not the second year plotted. 'Triplet' refers to the three 'lines' formed by points in Figure 3c. 


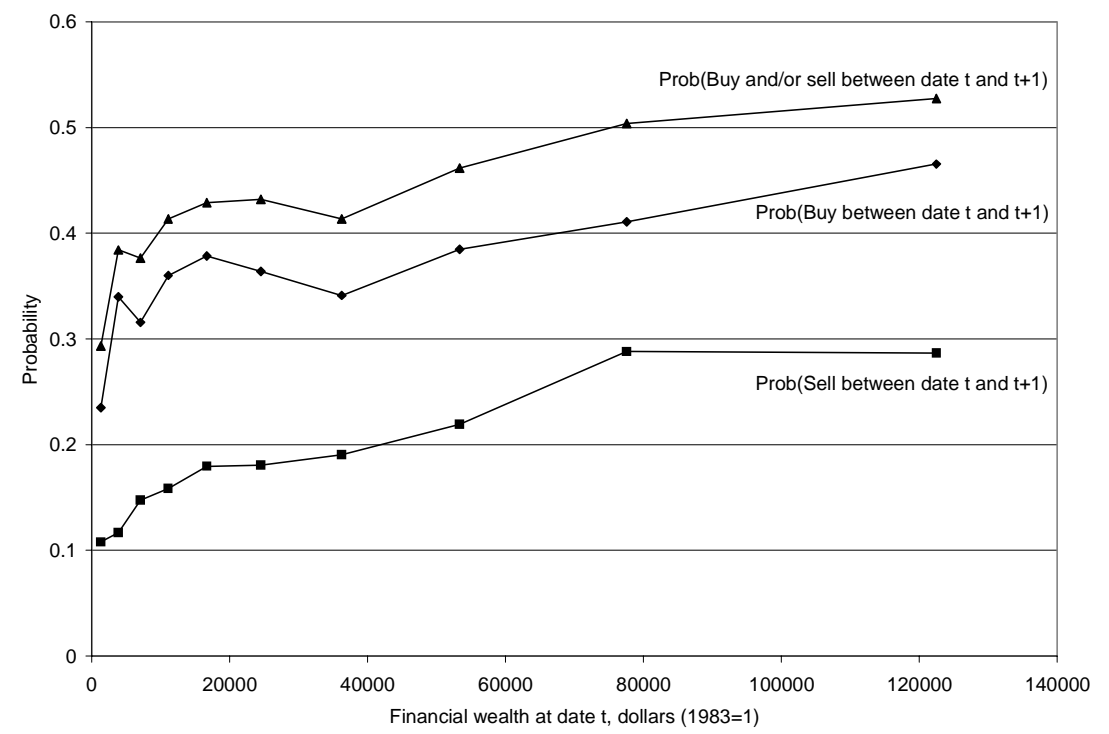

Figure 4: Trading frequencies. The graph documents higher trading frequencies for households with more financial wealth. It is based on data for 6770 households from the Consumer Expenditure Survey, 1982-96. These households held risky assets (defined as stock, bonds, mutual funds and other such securities) at the time they were interviewed as well as a year earlier. Households are sorted based on their financial wealth a year prior to the interview, and the three lines in the graph show the proportion of households in each financial wealth decile who bought, sold or both bought or sold risky asset during the one year period leading up to the survey. 


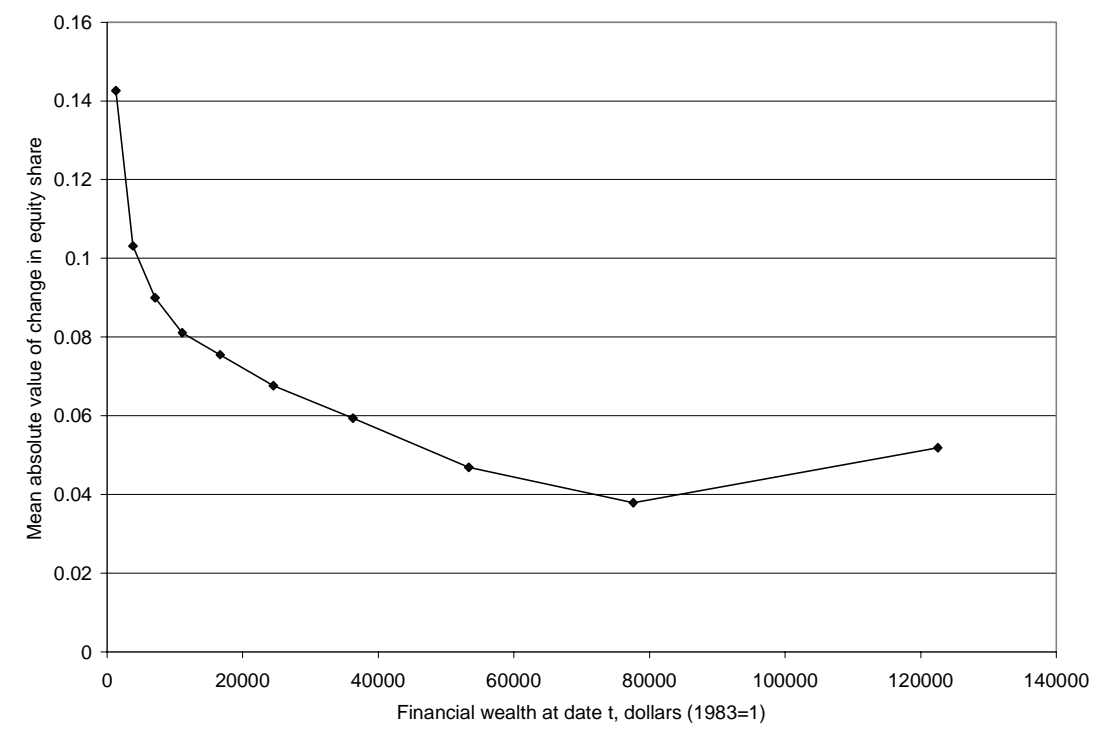

Figure 5: Trading range for the share of financial wealth invested in risky assets for holders of such assets. The graph documents a narrower range for the risky asset portfolio share for households with more financial wealth. It is based on data for 6770 households from the Consumer Expenditure Survey, 1982-96. These households held risky assets (defined as stock, bonds, mutual funds and other such securities) at the time they were interviewed as well as a year earlier. Households are sorted based on their financial wealth a year prior to the interview. The line in the graph shows for households in each financial wealth decile the cross sectional mean of the absolute value of the one year change in the risky asset portfolio share. 


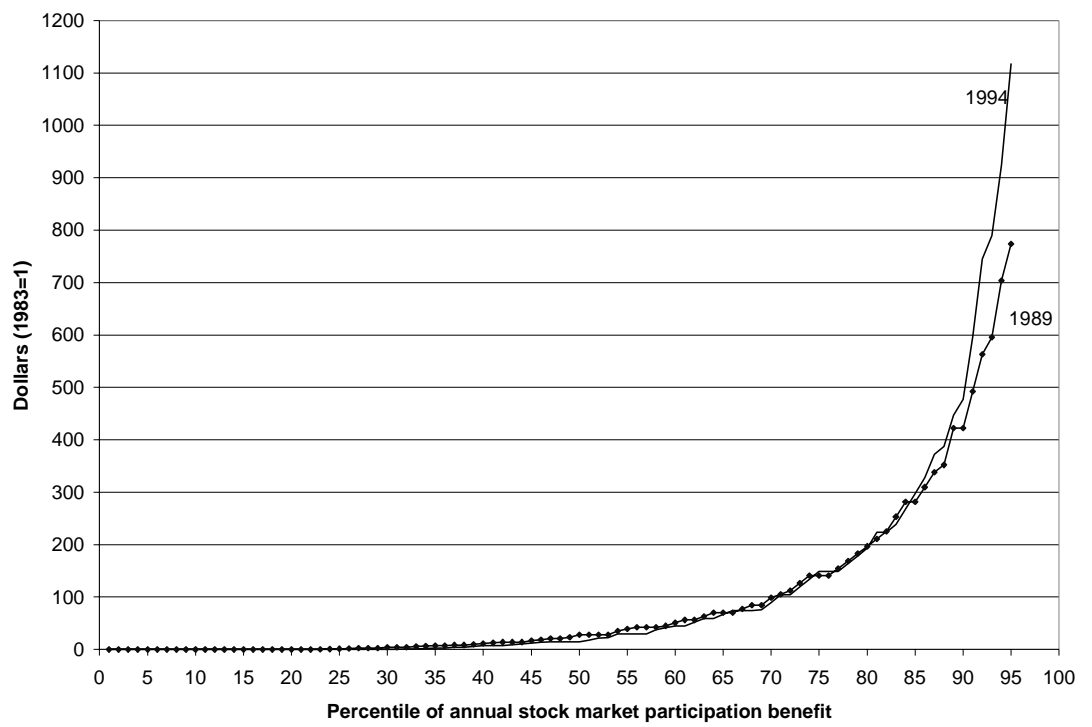

Figure 6: Stock market participation benefits for nonparticipants. Based on data from the 1989 and 1998 Panel Study of Income Dynamics, the figure shows estimates of the percentiles of the annual stock market participation benefit for households who chose not to participate in the stock market. The benefit is esimated as $W_{i t} \alpha_{t}\left(r_{s, i, t+1}^{c e}-r_{f, t+1}\right)$, where $W_{i t}$ is household $i$ 's financial wealth at date $t, \alpha_{t}$ is an assumed value for the proportion of financial wealth the household would have invested in stocks conditional on entry, and $r_{s, i, t+1}^{c e}-r_{f, t+1}$ is the certainty equivalent excess return of stocks over bonds assumed equal to 4 percent per year. I set $\alpha_{t}$ equal to the equal to the fraction of stock market wealth in total financial wealth of the PSID sample for year $t$, i.e. 35.9 percent in 1989 and 56.6 percent in 1994 . The interpretation of the lines shown is that if $x$ percent have benefits less than $y$ dollars, then an annual stock market participation cost of $y$ dollars is sufficient to explain the choices of $x$ percent of nonparticipants. 


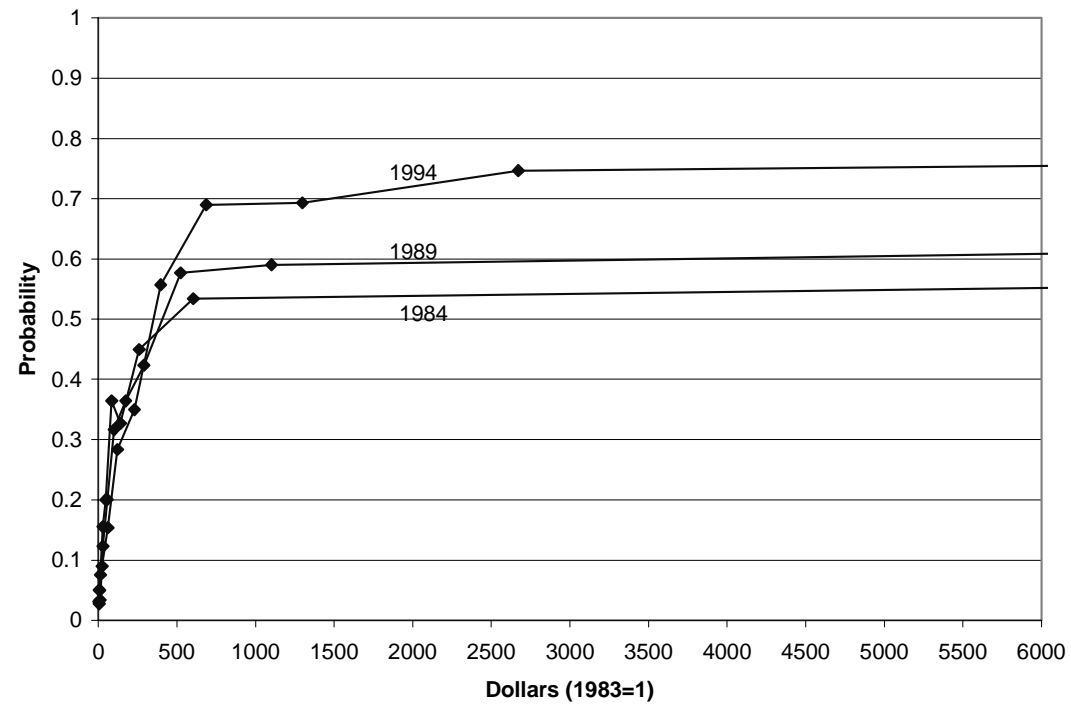

Figure 7: Estimated CDF of per period stock market participation cost. The figure shows the estimated cumulative distribution function for the per period stock market participation cost for each of the years 1984, 1989, and 1994 based on data from the Panel Study of Income Dynamics. The estimation is based on the assumption that households choose a portfolio share for stocks equal to the ratio of total stock market wealth to total financial wealth in the PSID in the year in question, if they enter the stock market. It is furthermore assumed that the certainty equivalent excess return of stocks over less risky financial assets is 4 percent per year. Households with zero financial wealth are excluded. 


\begin{tabular}{|c|c|c|c|c|c|c|c|c|}
\hline Year & Asset & $\begin{array}{l}\text { Pct holding } \\
\text { asset }\end{array}$ & $\begin{array}{c}\text { Median } \\
(\text { mean }) \\
\text { holdings }\end{array}$ & $\begin{array}{c}\text { Conditional } \\
\text { median (mean) } \\
\text { holdings, } \\
\text { dollars }\end{array}$ & $\begin{array}{c}\text { Median (mean) } \\
\text { pct of fin. } \\
\text { wealth, } \\
\text { dollars }\end{array}$ & $\begin{array}{c}\text { Conditional } \\
\text { median (mean) } \\
\text { pct of fin. } \\
\text { wealth }\end{array}$ & $\begin{array}{l}\text { Number of obs. } \\
\text { with positive } \\
\text { fin. wealth }\end{array}$ & $\begin{array}{c}\text { Total } \\
\text { number } \\
\text { of obs }\end{array}$ \\
\hline \multirow[t]{4}{*}{1984} & Stocks & 28.4 & $0(7640)$ & $6000(26902)$ & $0(12.3)$ & $37.5(43.4)$ & & \\
\hline & Bonds & 25.0 & $0(10516)$ & $3000(42209)$ & $0(9.9)$ & $31.6(39.8)$ & & \\
\hline & Cash & 97.9 & $3000(13527)$ & $3000(13822)$ & $100.0(77.8)$ & $100.0(79.5)$ & & \\
\hline & $\begin{array}{c}\text { Total fin. } \\
\text { wealth }\end{array}$ & & & $5000(31683)$ & & & 2581 & 3093 \\
\hline \multirow[t]{4}{*}{1989} & Stocks & 34.0 & $0(14914)$ & $10000(43819)$ & $0(14.9)$ & $38.5(43.6)$ & & \\
\hline & Bonds & 29.3 & $0(6748)$ & $5000(23384)$ & $0(12.3)$ & $35.5(42.4)$ & & \\
\hline & Cash & 98.0 & 4050(19824) & $4500(20222)$ & 100.0(72.9) & 100.0(74.4) & & \\
\hline & $\begin{array}{c}\text { Total fin. } \\
\text { wealth }\end{array}$ & & & $8650(41487)$ & & & 2800 & 3273 \\
\hline \multirow[t]{4}{*}{1994} & Stocks & 44.1 & $0(42255)$ & $21000(95881)$ & $0(24.4)$ & $54.6(55.2)$ & & \\
\hline & Bonds & 28.5 & $0(9228)$ & $8000(32957)$ & $0(11.7)$ & $33.33(41.8)$ & & \\
\hline & Cash & 96.4 & $5000(23327)$ & $6000(24254)$ & $80.0(63.9)$ & $83.9(66.5)$ & & \\
\hline & $\begin{array}{c}\text { Total fin. } \\
\text { wealth }\end{array}$ & & & $15000(74810)$ & & & 2825 & 3434 \\
\hline
\end{tabular}

The table gives summary statistics for the decision to hold stocks, bonds and cash, as well as the amounts invested. All data are based on the 1984, 1989, and 1994 Wealth Supplements to the Panel Study of Income Dynamics. 'Stocks' refer to shares of stock in publicly held corporations, mutual funds, and investment trusts, including stocks in IRAs. 'Bonds' refer to bond funds, cash value in life insurance policies, valuable collections for investment purposes, and rights in trusts and estates. 'Cash' refers to holdings in checking and savings accounts, money market bonds, or Treasury bills, including IRA's. Financial wealth is the sum of stocks, bonds, and cash. All numbers except the last column refer to households with positive financial wealth. 'Conditional median' refers to the median asset holding conditional on positive holdings of the asset in question.

Table 1: Summary statistics for households with positive financial wealth, PSID, 1984, 1989 and 1994 


\begin{tabular}{|c|c|c|c|c|c|c|}
\hline Years & Asset & $\begin{array}{c}\text { No.(pct) of households } \\
\text { with all financial } \\
\text { wealth in asset } \\
\text { both years } \\
\text { (corner of angle) }\end{array}$ & $\begin{array}{c}\text { No.(pct) of households } \\
\text { with no financial } \\
\text { wealth in asset } \\
\text { either year } \\
\text { (corner of angle) }\end{array}$ & $\begin{array}{l}\text { No.(pct) of households } \\
\text { on angle, except for } \\
\text { corner }\end{array}$ & $\begin{array}{l}\text { No.(pct) of } \\
\text { households } \\
\text { off angle }\end{array}$ & $\begin{array}{l}\text { Total } \\
\text { number } \\
\text { of } \\
\text { house- } \\
\text { holds }\end{array}$ \\
\hline \multirow[t]{3}{*}{$\begin{array}{c}\text { 1984-89 } \\
\text { panel }\end{array}$} & Stocks & & $\begin{array}{c}1006 \\
(53.2)\end{array}$ & $\begin{array}{c}469 \\
(24.8)\end{array}$ & $\begin{array}{c}417 \\
(22.0)\end{array}$ & $\begin{array}{c}1892 \\
(100.0)\end{array}$ \\
\hline & Bonds & & $\begin{array}{c}1039 \\
(54.9)\end{array}$ & $\begin{array}{c}599 \\
(31.7)\end{array}$ & $\begin{array}{c}254 \\
(13.4)\end{array}$ & $\begin{array}{c}1892 \\
(100.0)\end{array}$ \\
\hline & Cash & $\begin{array}{c}628 \\
(33.2)\end{array}$ & & $\begin{array}{c}617 \\
(32.6)\end{array}$ & $\begin{array}{c}647 \\
(34.2)\end{array}$ & $\begin{array}{c}1892 \\
(100.0)\end{array}$ \\
\hline \multirow[t]{4}{*}{$\begin{array}{c}\text { 1989-94 } \\
\text { panel }\end{array}$} & Stocks & & $\begin{array}{c}888 \\
(43.1)\end{array}$ & $\begin{array}{c}568 \\
(27.6)\end{array}$ & $\begin{array}{c}603 \\
(29.3)\end{array}$ & $\begin{array}{c}2059 \\
(100.0)\end{array}$ \\
\hline & Bonds & & $\begin{array}{c}1080 \\
(52.5)\end{array}$ & $\begin{array}{c}687 \\
(33.4)\end{array}$ & $\begin{array}{c}292 \\
(14.2)\end{array}$ & $\begin{array}{c}2059 \\
(100.0)\end{array}$ \\
\hline & Cash & $\begin{array}{c}542 \\
(26.3)\end{array}$ & & $\begin{array}{c}656 \\
(31.9)\end{array}$ & $\begin{array}{c}861 \\
(41.8)\end{array}$ & $\begin{array}{c}2059 \\
(100.0)\end{array}$ \\
\hline & & $\begin{array}{c}\text { No.(pct) of households } \\
\text { with all financial } \\
\text { wealth in asset } \\
\text { all three years } \\
\text { (center of triplet) }\end{array}$ & $\begin{array}{c}\text { No.(pct) of households } \\
\text { with no financial } \\
\text { wealth in asset } \\
\text { any of the years } \\
\text { (center of triplet) }\end{array}$ & $\begin{array}{c}\text { No.(pct) of households } \\
\text { on triplet, except for } \\
\text { center }\end{array}$ & $\begin{array}{l}\text { No.(pct) of } \\
\text { households } \\
\text { off triplet }\end{array}$ & Total \\
\hline \multirow{4}{*}{$\begin{array}{c}1984 \\
-89-94 \\
\text { panel }\end{array}$} & Stocks & & 516 & 341 & 588 & 1445 \\
\hline & & & $(35.7)$ & $(23.6)$ & $(40.7)$ & $(100.0)$ \\
\hline & Bonds & & 604 & 462 & 379 & 1445 \\
\hline & Cash & $\begin{array}{c}268 \\
(18.6)\end{array}$ & (41.8) & $\begin{array}{c}(32.0) \\
356 \\
(24.6)\end{array}$ & $\begin{array}{c}(26.2) \\
821 \\
(56.8)\end{array}$ & $\begin{array}{c}(100.0) \\
1445 \\
(100.0)\end{array}$ \\
\hline
\end{tabular}

The table contains summary statistics characterizing the amount of nonparticipation, entry, and exit in the markets for stocks, bonds, and cash, based on data from the Panel Study of Income Dynamics. The data are further described by Figure 1, 2, and 3. Only households with positive financial wealth are included. The terminology 'angle' refers to the L-shaped formation of point in Figures 1a,b, 2a,b, and 3a,b. 'Triplet' refers to the three 'lines' of points in Figures 1c, 2c, and 3c. The top part of the table focuses on the two 2-year panels 1984-1989, and 1989-1994. The bottom part focuses on the 3-year panel 1984-1989-1994.

Table 2: Summary statistics documenting nonparticipation, entry and exit in the PSID 


\begin{tabular}{|c|c|c|c|c|c|}
\hline & \multicolumn{2}{|c|}{ Participation } & & \multicolumn{2}{|c|}{ Equity Share } \\
\hline & Coefficient & $\mathrm{t}$ & & Coefficient & $\mathrm{t}$ \\
\hline Cond. mean of nonfin. inc. & 0.0087 & 3.25 & $\begin{array}{l}\text { Cond. mean of nonfin. inc./ } \\
\text { Financial wealth }\end{array}$ & 0.0075 & 2.56 \\
\hline Cond. std. of nonfin. inc. & -0.0093 & -3.01 & $\begin{array}{l}\text { Cond. std. of nonfin. inc./ } \\
\text { Financial wealth }\end{array}$ & -0.0223 & -2.78 \\
\hline Lagged part. decision & 0.8233 & 7.18 & & & \\
\hline Lagged $\$$ stockholdings & 0.0193 & 3.00 & & & \\
\hline Lagged $\$$ stockholdings ${ }^{2}$ & -0.0001 & -2.75 & & & \\
\hline Age of head & 0.0156 & 0.67 & Age of head & 0.0070 & 0.86 \\
\hline Age of head ${ }^{2}$ & -0.0002 & -0.95 & Age of head ${ }^{2}$ & $-2.91 \mathrm{e}-4$ & -0.38 \\
\hline $\mathrm{D}($ education $=16+$ years $)$ & 0.6032 & 2.39 & $\mathrm{D}$ (education $=16+$ years $)$ & 0.1413 & 1.29 \\
\hline $\mathrm{D}($ education $=13-15$ years $)$ & 0.3963 & 1.59 & $\mathrm{D}($ education $=13-15$ years $)$ & 0.1507 & 1.39 \\
\hline $\mathrm{D}($ education $=9-12$ years $)$ & 0.1957 & 0.79 & $\mathrm{D}($ education $=9-12$ years $)$ & 0.0942 & 0.88 \\
\hline $\mathrm{D}($ race $=$ white $)$ & 0.5028 & 2.14 & $\mathrm{D}($ race $=$ white $)$ & 0.1074 & 1.16 \\
\hline Real financial wealth & 0.0090 & 5.07 & Real financial wealth & -0.0007 & -1.57 \\
\hline Real financial wealth ${ }^{2}$ & $-1.13 e-5$ & -3.59 & Real financial wealth ${ }^{2}$ & $1.86 \mathrm{e}-6$ & 2.34 \\
\hline \multirow[t]{2}{*}{ Constant } & -2.1484 & -3.28 & Constant & 0.0273 & 0.10 \\
\hline & & & Lambda & -0.0988 & -2.25 \\
\hline
\end{tabular}

The table shows the baseline estimation of a sample selection model of stock market investment. The equation for participating in the stock market is: $S_{i t}^{*}=x_{i t}^{\prime} \beta+\delta_{1} S_{i, t-1}+\delta_{2} D_{i, t-1}+\delta_{3} D_{i, t-1}^{2}+\nu_{i t}, \mathrm{~S}_{i t}=1$ if $S_{i t}^{*} \geq 0,0$ otherwise. $S_{i t}$ is the indicator variable for whether household $i$ participates in the stock market at date $t, D_{i, t-1}$ is the dollar amount invested last period if any, and $x_{i t}$ are regressors. The equation for the equity share (the share $\alpha_{i t}$ of financial wealth invested in stocks conditional on participation) is: $\alpha_{i t}=w_{i t}^{\prime} \gamma+u_{i t}$, observed if $S_{i t}=1$, where $w_{i t}$ are regressors. The first three columns of the table refer to the decision to participate in the stock market or not. The last three columns refer to the equity share. The data used is a sample of 1081 households from the Panel Study of Income Dynamics. Households included in the sample are those who had positive financial wealth in 1984 and 1989, for which data on income and demographic variables were available for all years in the period 1982-1992 and who had no change in head or spouse during this period. Observations with moments of nonfinancial income in the top or bottom one percent are dropped. The portfolio data used to calculate the dependent variables are from 1989, with 1984 values used as lags. The conditional mean and standard deviations of nonfinancial income are calculated based on data for the four income growth observations 1988-89, 1989-90, 1990-91, 1991-92. Dollar amounts are in thousands. In the bottom line 'lambda' is the product of the correlation of the error terms in the two equations and the variance of the error term in the equity share equation. This product would be zero if stockholding households were a random subgroup of the population. The two equations are estimated jointly using maximum likelihood estimation.

Table 3: Sample selection model for the decision to hold stocks, and the proportion of financial wealth invested in stocks 


\begin{tabular}{|c|c|c|c|c|c|}
\hline & \multicolumn{2}{|c|}{ Participation } & & \multicolumn{2}{|c|}{ Equity Share } \\
\hline & Coefficient & $\mathrm{t}$ & & Coefficient & $\mathrm{t}$ \\
\hline Cond. mean of nonfin. inc. & 0.0105 & 2.52 & $\begin{array}{c}\text { Cond. mean of nonfin. inc./ } \\
\text { Financial wealth }\end{array}$ & 0.0488 & 2.43 \\
\hline Cond. std. of nonfin. inc. & -0.0110 & -0.78 & $\begin{array}{l}\text { Cond. std. of nonfin. inc./ } \\
\text { Financial wealth }\end{array}$ & -0.0973 & -1.76 \\
\hline Lagged part. decision & 0.8635 & 10.41 & & & \\
\hline Lagged $\$$ stockholdings & 0.0143 & 2.52 & & & \\
\hline Lagged $\$$ stockholdings ${ }^{2}$ & -0.0001 & -2.62 & & & \\
\hline Age of head & 0.0123 & 0.64 & Age of head & 0.0059 & 0.77 \\
\hline Age of head ${ }^{2}$ & -0.0002 & -0.91 & Age of head ${ }^{2}$ & $6.94 \mathrm{e}-6$ & 0.09 \\
\hline $\mathrm{D}($ education $=16+$ years $)$ & 0.5946 & 2.74 & $\mathrm{D}($ education $=16+$ years $)$ & 0.0849 & 0.80 \\
\hline $\mathrm{D}($ education $=13-15$ years $)$ & 0.3907 & 1.83 & $\mathrm{D}($ education $=13-15$ years $)$ & 0.1080 & 1.04 \\
\hline $\mathrm{D}($ education $=9-12$ years $)$ & 0.2037 & 0.97 & $\mathrm{D}($ education $=9-12$ years $)$ & 0.0029 & 0.03 \\
\hline $\mathrm{D}($ race $=$ white $)$ & 0.5105 & 2.69 & $\mathrm{D}($ race $=$ white $)$ & 0.0756 & 0.78 \\
\hline Real financial wealth & 0.0093 & 6.12 & Real financial wealth & $6.13 \mathrm{e}-5$ & 0.12 \\
\hline Real financial wealth ${ }^{2}$ & $-1.16 \mathrm{e}-5$ & -5.03 & Real financial wealth ${ }^{2}$ & $7.21 \mathrm{e}-7$ & 0.83 \\
\hline \multirow[t]{2}{*}{ Constant } & -2.1482 & -4.02 & Constant & 0.0058 & 0.02 \\
\hline & & & Lambda & -0.1774 & -3.07 \\
\hline
\end{tabular}

The table shows the results of estimating the sample selection model of stock market investment using instrumental variables estimation. The equation for participating in the stock market is: $S_{i t}^{*}=x_{i t}^{\prime} \beta+\delta_{1} S_{i, t-1}+$ $\delta_{2} D_{i, t-1}+\delta_{3} D_{i, t-1}^{2}+\nu_{i t}, \mathrm{~S}_{i t}=1$ if $S_{i t}^{*} \geq 0,0$ otherwise. $S_{i t}$ is the indicator variable for whether household $i$ participates in the stock market at date $t, D_{i, t-1}$ is the dollar amount invested last period if any, and $x_{i t}$ are regressors. The equation for the equity share (the share $\alpha_{i t}$ of financial wealth invested in stocks conditional on participation) is: $\alpha_{i t}=w_{i t}^{\prime} \gamma+u_{i t}$, observed if $S_{i t}=1$, where $w_{i t}$ are regressors. The first three columns of the table refer to the decision to participate in the stock market or not. The last three columns refer to the equity share. The data used is a sample of 1081 households from the Panel Study of Income Dynamics. Households included in the sample are those who had positive financial wealth in 1984 and 1989, for which data on income and demographic variables were available for all years in the period 1982-1992 and who had no change in head or spouse during this period. Observations with moments of nonfinancial income in the top or bottom one percent are dropped. The portfolio data used to calculate the dependent variables are from 1989, with 1984 values used as lags. The conditional mean and standard deviations of nonfinancial income are calculated based on data for the four income growth observations 1988-89, 1989-90, 1990-91, 1991-92. Dollar amounts are in thousands. In the bottom line 'lambda' is the product of the correlation of the error terms in the two equations and the variance of the error term in the equity share equation. This product would be zero if stockholding households were a random subgroup of the population. The two equations are estimated separately with the participation equation estimated using the estimator of Amemiya (1978) and the equity share equation estimated using the estimator of Lee (1981) which account for potential selection effects. In each equation the instruments used are the lagged moments of nonfinancial income based on the five income growth observations 1983-84,...,1987-88. The use of instrumentation is motivated by measurement and estimation error in the estimated conditional moments of nonfinancial income included as regressors.

Table 4: Sample selection model for the decision to hold stocks, and the proportion of financial wealth invested in stocks, instrumental variables estimations 


\begin{tabular}{|c|c|c|c|c|c|}
\hline & \multicolumn{2}{|c|}{ Participation } & & \multicolumn{2}{|c|}{ Equity Share } \\
\hline & Coefficient & $\mathrm{t}$ & & Coefficient & $\mathrm{t}$ \\
\hline Cond. mean of nonfin. inc. & 0.0086 & 3.21 & $\begin{array}{l}\text { Cond. mean of nonfin. inc./ } \\
\text { Financial wealth }\end{array}$ & 0.0085 & 2.41 \\
\hline Cond. std. of nonfin. inc. & -0.0091 & -2.96 & $\begin{array}{l}\text { Cond. std. of nonfin. inc./ } \\
\text { Financial wealth }\end{array}$ & -0.0245 & -2.67 \\
\hline $\begin{array}{l}\text { (Cond. mean of nonfin. inc.) } \\
{ }_{*} \text { Correlation }\end{array}$ & 0.0016 & 0.56 & $\begin{array}{l}\text { (Cond. mean of nonfin. inc. } \\
\text { /Financial wealth)*Correlation }\end{array}$ & 0.0021 & 0.47 \\
\hline Lagged part. decision & 0.8272 & 7.21 & & & \\
\hline Lagged $\$$ stockholdings & 0.0194 & 3.02 & & & \\
\hline Lagged $\$$ stockholdings $^{2}$ & -0.0001 & -2.77 & & & \\
\hline Age of head & 0.0161 & 0.69 & Age of head & 0.0069 & 0.86 \\
\hline Age of head ${ }^{2}$ & -0.0002 & -0.96 & Age of head ${ }^{2}$ & $-2.83 e-5$ & -0.37 \\
\hline $\mathrm{D}($ education $=16+$ years $)$ & 0.6002 & 2.38 & $\mathrm{D}($ education $=16+$ years $)$ & 0.1402 & 1.28 \\
\hline $\mathrm{D}$ (education $=13-15$ years $)$ & 0.3945 & 1.58 & $\mathrm{D}($ education $=13-15$ years $)$ & 0.1512 & 1.39 \\
\hline $\mathrm{D}($ education $=9-12$ years $)$ & 0.1943 & 0.79 & $\mathrm{D}($ education $=9-12$ years $)$ & 0.0937 & 0.87 \\
\hline $\mathrm{D}($ race $=$ white $)$ & 0.5024 & 2.14 & $\mathrm{D}($ race $=$ white $)$ & 0.1037 & 1.11 \\
\hline Real financial wealth & 0.0090 & 5.04 & Real financial wealth & -0.0007 & -1.53 \\
\hline Real financial wealth ${ }^{2}$ & $-1.13 e-5$ & -3.59 & Real financial wealth ${ }^{2}$ & $1.84 \mathrm{e}-6$ & 2.30 \\
\hline \multirow[t]{2}{*}{ Constant } & -2.1573 & -3.30 & Constant & 0.0302 & 0.12 \\
\hline & & & Lambda & -0.0996 & 0.04 \\
\hline
\end{tabular}

The table shows the results of adding variables measuring the covariance of nonfinancial income with the real value weighted NYSE stock return to the sample selection model of stock market investment. The equation for participating in the stock market is: $S_{i t}^{*}=x_{i t}^{\prime} \beta+\delta_{1} S_{i, t-1}+\delta_{2} D_{i, t-1}+\delta_{3} D_{i, t-1}^{2}+\nu_{i t}, \mathrm{~S}_{i t}=1$ if $S_{i t}^{*} \geq 0,0$ otherwise. $S_{i t}$ is the indicator variable for whether household $i$ participates in the stock market at date $t, D_{i, t-1}$ is the dollar amount invested last period if any, and $x_{i t}$ are regressors. The equation for the equity share (the share $\alpha_{i t}$ of financial wealth invested in stocks conditional on participation) is: $\alpha_{i t}=w_{i t}^{\prime} \gamma+u_{i t}$, observed if $S_{i t}=1$, where $w_{i t}$ are regressors. The first three columns of the table refer to the decision to participate in the stock market or not. The last three columns refer to the equity share. The data used is a sample of 1081 households from the Panel Study of Income Dynamics. Households included in the sample are those who had positive financial wealth in 1984 and 1989, for which data on income and demographic variables were available for all years in the period 1982-1992 and who had no change in head or spouse during this period. Observations with moments of nonfinancial income in the top or bottom one percent are dropped. The portfolio data used to calculate the dependent variables are from 1989, with 1984 values used as lags. The conditional mean and standard deviations of nonfinancial income are calculated based on data for the four income growth observations 1988-89, 1989-90, 1990-91, 1991-92. Dollar amounts are in thousands. In the bottom line 'lambda' is the product of the correlation of the error terms in the two equations and the variance of the error term in the equity share equation. This product would be zero if stockholding households were a random subgroup of the population. The two equations are estimated jointly using maximum likelihood estimation.

Table 5: Sample selection model for the decision to hold stocks, and the proportion of financial wealth invested in stocks, estimation including covariance variables 


\begin{tabular}{ccccc}
\hline \hline & \multicolumn{2}{c}{ Participation, 1995 data } & \multicolumn{2}{c}{ Participation, 1998 data } \\
\cline { 2 - 5 } & Coefficient & $\mathrm{t}$ & Coefficient & $\mathrm{t}$ \\
\hline Normal income & 0.0068 & 7.40 & 0.0066 & 6.91 \\
D(next year's income uncertain) & -0.1412 & -2.66 & -0.2475 & -4.45 \\
D(deterred from applying for credit) & -0.2909 & -3.95 & -0.1405 & -1.91 \\
D(turned down for credit) & -0.1107 & -1.33 & 0.1355 & 1.71 \\
Age of head & 0.0129 & 1.42 & 0.0417 & 4.74 \\
Age of head & -0.0001 & -1.56 & -0.0004 & -5.02 \\
D(education=16+ years) & 0.4212 & 3.54 & 0.5081 & 3.88 \\
D(education=13-15 years) & 0.5800 & 4.70 & 0.6745 & 4.98 \\
D(education=9-12 years) & 0.8108 & 6.53 & 0.6734 & 4.90 \\
D(race=white) & 0.2541 & 3.94 & 0.2533 & 3.98 \\
Financial wealth & 0.0019 & 10.08 & 0.0034 & 12.46 \\
Financial wealth & $-1.09 \mathrm{e}-7$ & -9.48 & $-1.86 \mathrm{e}-8$ & -10.68 \\
D(highest risk aversion category) & 0.0586 & 0.41 & 0.1873 & 1.47 \\
D(second highest risk aversion category) & -0.0762 & -0.57 & -0.3533 & -2.98 \\
D(second lowest risk aversion category) & -0.6047 & -4.48 & -0.8110 & -6.68 \\
Constant & -1.3101 & -4.71 & -1.7705 & -6.42 \\
\hline
\end{tabular}

The table shows the results of estimating a probit model of stock market participation using two cross sections of data from the 1995 and 1998 Survey of Consumer Finances. The first regressor 'normal income' is the response to the question "About what would your income have been if it had been a normal year?". The dummy for next year's income being uncertain is based on the question "At this time, do you have a good idea of what your income for next year will be?". The next two regressors are measures of being borrowing constrained. $\mathrm{D}$ (deterred from applying for credit) is one if during the past five year's the household thought of applying for credit but changed its mind thinking it may be turned down. $\mathrm{D}$ (turned down for credit) is one if the household has been turned down for credit during the last five years (and been unable to borrow the requested amount from another lender). Households included in the two samples are those who had positive financial wealth and who did not have normal income in the highest or lowest percentile. The estimations are done using all SCF imputations for missing values and t-statistics are correspondingly divided by the square root of 5 . For comparison with the PSID, the estimations use SCF weights. The number of observations used is 3379 for the 1995 SCF and 3444 for the 1998 SCF. Dollar amounts are in thousands.

Table 6: Probit model for the decision to hold stocks, alternative data set (Survey of Consumer Finances 1995, 1998) 


\begin{tabular}{ccc}
\hline \hline & \multicolumn{2}{c}{ Participation } \\
\cline { 2 - 3 } & Coefficient & $\mathrm{t}$ \\
\hline Cond. mean of nonfin. inc. & 0.0093 & 3.678 \\
& & \\
Cond. std. of nonfin. inc. & -0.0101 & -3.398 \\
& & \\
Lagged part. decision & 1.0995 & 3.514 \\
Lagged \$ stockholdings & 0.0031 & 0.44 \\
Lagged \$ stockholdings & \\
Age of head & $2.26 \mathrm{e}-5$ & -0.972 \\
Age of head & 0.0119 & 1.973 \\
D(education=16+ years) & -0.0002 & -2.586 \\
D(education=13-15 years) & 0.5615 & 2.248 \\
D(education=9-12 years) & 0.3601 & 1.522 \\
D(race=white) & 0.1720 & 0.733 \\
Real financial wealth & 0.5140 & 2.425 \\
Real financial wealth & \\
Constant & 0.0103 & 5.817 \\
Covariance of the error terms for $S_{1989}$ and $S_{1984}$ & $-1.26 \mathrm{e}-5$ & -3.903 \\
Covariance of the error terms for $S_{1984}$ and $D_{1984}$ & -0.0849 & -6.009 \\
Covariance of the error terms for $S_{1989}$ and $D_{1984}$ & -0.0630 & -0.58 \\
& & -0.87 \\
&
\end{tabular}

In order to determine if the significance of the lagged stock market participation and dollar stockholdings for the current stock market participation is due to unobserved individual effects rather than fixed and variable transactions costs, the probit model of stock market participation is reestimated using a generalized version the dynamic probit estimator of Heckman (1981). The estimation involves specifying an equation for the previous period's participation decision, for the previous period's amount invested in stocks, and for the current period's participation decision. Allowing for correlation between the error terms caused by potential unobserved individual effects prevents the lags from being spuriously significant. The lagged amount invested in stocks now has a negative effect on the current participation decision. This indicates that the positive effect found earlier was spurious and due to unobserved individual effects. Data from the Panel Study of Income Dynamics. N=1081.

Table 7: Probit model for the decision to hold stocks, accounting for unobserved individual effects. 